\title{
Accounting for Fertility Decline During the Transition to Growth *
}

\author{
Matthias Doepke \\ UCLA
}

October 2003

\begin{abstract}
In every developed country, the economic transition from pre-industrial stagnation to modern growth was accompanied by a demographic transition from high to low fertility. Even though the overall pattern is repeated, there are large cross-country variations in the timing and speed of the demographic transition. What accounts for falling fertility during the transition to growth? To answer this question, this paper develops a unified growth model which delivers a transition from stagnation to growth, accompanied by declining fertility. The model is used to determine whether government policies that affect the opportunity cost of education can account for crosscountry variations in fertility decline. Among the policies considered, education subsidies have only minor effects, while accounting for child-labor regulations is crucial. Apart from influencing fertility, the policies also have large effects on the evolution of the income distribution in the course of development.
\end{abstract}

JEL Classification: I20, J13, O14, O40

Keywords: Growth, Fertility, Education, Child Labor, Inequality.

${ }^{*}$ Workshop participants at Chicago, the SED annual meetings, the Max Planck Institute for Demography, the Federal Reserve Bank of Minneapolis, Wharton, Pennsylvania, Boston University, Western Ontario, UCLA, Stanford, Rochester, Virginia, UCL, Cambridge, IIES, Illinois, Minnesota, USC, UC Riverside, Duke, and Brown provided many helpful comments. I also benefited from suggestions by Sylvain Dessy, Lee Ohanian, Daria Zakharova, and Rui Zhao. Financial support by the National Science Foundation is gratefully acknowledged. E-mail: doepke@econ.ucla.edu. Address: UCLA, Department of Economics, 405 Hilgard Ave, Los Angeles, CA 90095-1477. 


\section{Introduction}

Fertility decline is a universal feature of development. Every now industrialized country experienced a demographic transition form high to low fertility, accompanied by a large rise in life expectancy. Most developing countries are in the midst of their demographic transition today. Until a short time ago, economic and demographic change during development were studied in isolation: researchers studying economic growth tended to abstract from population dynamics, while demographers concentrated on explanations for the demographic transition. More recently, economists have started to recognize important interactions between demographic and economic change, and responded by developing unified models which encompass both the economic takeoff from stagnation to growth, and the demographic transition from high to low fertility.

Accounting for fertility behavior is an important challenge for theories of development, because demographic change affects the economic performance of a country in a number of ways. The most familiar concern is that high population growth dilutes the stock of physical capital, and therefore exerts a negative effect on income per capita. A perhaps even more important channel works through the accumulation of human capital. High fertility rates tend to be associated with low education; countries with a high fertility rate therefore accumulate less human capital. A third channel from the demographic transition to growth works through changes in the age structure of the population. Rapid fertility decline lowers the dependency ratio, since initially both the old-age and child-age cohorts are small relative to the working-age population. Hence, countries that undergo a fast fertility transition experience a sizable, if temporary, boost to their level of output per capita, because the size of the labor force increases faster than the population as a whole. ${ }^{1}$

The focus of this paper is to understand why different countries undergo different demographic transitions. Despite the fact that the overall pattern is repeated, the speed and timing of fertility decline during the transition from stagnation to growth differs widely across countries. An example that will be used repeatedly throughout the paper is the contrast of Brazil and South Korea. From the 1950s to the 1980s, the two countries had a very similar growth experience. Substantial growth in income per capita started at the same time, and throughout the late 1960s and 1970s both countries were considered to be "miracle economies," with growth rates of output per capita exceeding five percent per

\footnotetext{
${ }^{1}$ Bloom and Williamson (1998) argue that this cohort effect accounts for a large proportion of East Asia's "economic miracle" between 1960 and 1990.
} 
year. Initially, fertility was similar as well, with a total fertility rate of 6.0 in both countries in 1960. After 1960, however, fertility started to drop fast in Korea, while fertility decline was much slower and more spread out in Brazil. Figure 1 plots the total fertility rate relative to GDP per capita. As a benchmark, data from England, the first country to experience the transition from stagnation to growth, is also included in the graph. Relative to income per capita, fertility fell much faster in Korea than it had in England, whereas the decline is much slower in Brazil. Throughout most of the transition, for a given level of income per capita the fertility differential between Brazil and Korea exceeds two children per family. ${ }^{2}$

Why did the demographic transition proceed so much faster in Korea than in Brazil? Existing theories of growth and fertility decline do not answer this question, since they imply that fertility is a fixed function of income per capita during the transition, so that the fertility transition should be identical across countries. The aim of this paper is to explore the role of one specific explanation, namely differences in educational and childlabor policies, in explaining cross-country variations in the speed of fertility decline. ${ }^{3}$

The motivation for this explanation is twofold. First, most economic models of fertility choice are built on the notion of a quantity-quality tradeoff between the number of children and education per child (for example, Becker and Barro 1988). If fertility and education are indeed joint decisions, government policies that affect the opportunity cost of education should have a first-order effect on fertility. Second, we do in fact observe large variations in educational and child-labor policies across countries during the transition to growth. Most countries introduce education and child-labor reforms at some point during their development, but the extent and timing of these reforms varies widely. Brazil and Korea are once again drastic examples. Starting in the mid-fifties (after the Korean war), the two countries were polar opposites in terms of their educational and child labor policies. In Korea, child labor was almost completely eradicated by 1960, and large amounts of resources were devoted to building a public education system. In terms of educational outcomes (enrollment rates, literacy rates, average schooling) Korea was far ahead of other countries at a comparable level of development. Brazil, on the other hand, spent relatively little on basic education, and was lagging far behind comparable coun-

\footnotetext{
${ }^{2}$ Similar variations in the speed of fertility decline can be observed across many other countries. The transition was especially rapid in the East Asian "miracle" economies such as Taiwan, Hong Kong, and Singapore. Examples of a slow transition include Malaysia, Turkey, Mexico, and Costa Rica.

${ }^{3}$ In concentrating on the role of political variables, I abstract from other factors that could also affect the fertility transition. The aim here is to derive the implications of different educational policies on the fertility transition in isolation; the analysis does not rule out that other factors could also matter.
} 
tries in terms of educational outcomes. Child labor laws were lax and loosely enforced, so that child labor was widespread well into the 1990s. ${ }^{4}$

In order to examine the role of educational policies during the fertility transition, I develop a growth model that generates a phase of Malthusian stagnation combined with high fertility, followed by a transition to a growth regime and low fertility. The model is used to explore the degree to which child-labor restrictions and education subsidies can account for cross-country variations in the timing and the speed of fertility decline. The theoretical framework consists of three key elements: An agricultural production function, an industrial production function, and a quantity-quality fertility model. The main role of the technology side of the model, which derives from Hansen and Prescott (2002), is to generate an economic transition from stagnation to growth. The preference side of the model is based on the dynastic utility framework introduced by Becker and Barro (1988). Parents are altruistic and decide on the number and on the education level of their children, i.e., they face a quantity-quality tradeoff. This tradeoff is essential for generating fertility decline during the transition to growth.

To assess whether the effects of government policies are quantitatively important, the model is calibrated to data. By simulating the calibrated model under different policy regimes, I examine how educational and child labor policies affect the fertility transition. The main finding is that these policies indeed have large effects on fertility during the transition to growth. If parents have to pay for schooling and child labor is unrestricted, the fertility transition starts later and progresses slowly. In contrast, if education is publicly provided and restrictions on child labor are strict, fertility declines rapidly. Quantitatively, education subsidies have a relatively minor impact, but accounting for child-labor restrictions turns out to be crucial.

I also examine what happens if the same policy reforms that were instituted at the start of the take-off in Korea are introduced with a delay. This "English" regime is designed to capture the fact that in England industrialization started before 1800, whereas the main policy changes were only introduced after about 1870. In the model, with a delayed policy reform fertility stays high in the early phase of the transition, and declines rapidly once the reforms are introduced. This pattern is consistent with the evolution of fertility in England between 1800 and 1914. The timing of the education reform also has large effects on the income distribution. If the reform takes place at the start of the transition, inequality stays low throughout the transition. With a delayed reform, a Kuznets curve emerges:

\footnotetext{
${ }^{4}$ See Appendix $\mathrm{C}$ for a description of educational policies and outcomes in Brazil and Korea.
} 
inequality first increases rapidly, and then decreases once the policies are changed.

This research adds to an emerging literature on long-run growth and population dynamics. Galor and Weil (2000), Kögel and Prskawetz (2001), Jones (2001), Hansen and Prescott (2002), and Tamura (2002) all develop models that generate a transition from pre-industrial stagnation to modern growth, accompanied by a demographic transition. To the extent that fertility is endogenous, these models also have the feature that a rise in the return to human capital is the driving force behind fertility decline. ${ }^{5}$ However, the models imply fertility is a fixed function of income per capita during the transition to growth, which is inconsistent with cross-country variations in fertility decline.

Relative to the existing literature, the main contribution of this paper is to develop a quantitative model of the transition from stagnation to growth which can be used to understand cross-country differences in the transition experience. ${ }^{6}$ Apart from being interesting in its own right, addressing cross-country differences also serves as a test of the theory: if we find the true mechanism that explains the fertility decline associated with development, we should also be able to explain why the fertility decline differed so much across countries. To this end, the results in this paper lend support to the quality-quantity model of fertility choice in general.

The results also provide a new perspective on the growth-and-inequality debate. The same policies that influence fertility choice in the model also have large effects on the evolution of the income distribution during the transition. The main driving force behind the distributional effects is the endogenous fertility differential between skilled and unskilled parents. Through this differential, educational policies have large long-run effects on the relative number of skilled and unskilled people, and therefore on the skill premium. ${ }^{7}$

The rest of the paper is organized as follows. The next section introduces the model. Section 3 derives a number of theoretical properties of the model, and Section 4 discusses

\footnotetext{
${ }^{5}$ Alternative theories are based on changes in gender roles, see Galor and Weil (1996) and Lagerlöf (2002), and the old-age security motive, see Morand (1999).

${ }^{6}$ Other recent studies which use quantitative theory to evaluate growth models with endogenous population include Fernández-Villaverde (2001) on the role of capital-skill complementarity for explaining fertility decline, Greenwood and Seshadri (2002) on the U.S. demographic transition, and Ngai (2000) on barriers to technology adoption.

${ }^{7}$ Fertility differentials play an important role in Moav (2001), who points to cross-country fertility differences as an explanation for persistent income inequality, and de la Croix and Doepke (2003), who link fertility differentials within a country to economic growth. Interactions between fertility differentials and inequality are also the focus of Dahan and Tsiddon (1998), Kremer and Chen (1999), and Veloso (1999).
} 
the behavior of the model in the Malthusian regime, the growth regime, and the transition between the two. In Section 5 I discuss the calibration procedure, and Section 6 uses the calibrated model to assess the effect of government policies during the transition. Section 7 concludes.

\section{The Model}

The economy is populated by overlapping generations of people who live for two periods, childhood and adulthood. Children receive education or work, do not enjoy any utility, and do not get to decide anything. Adults can be either skilled or unskilled, depending on their education. In each period there is a continuum of adults of each type; $N_{S}$ is the measure of skilled adults, and $N_{U}$ is the measure of unskilled adults. Adults decide on their consumption, labor supply, and on the number and the education of their children.

\section{Technology}

The single consumption good in this economy can be produced with two different methods. There is an agricultural technology that uses skilled labor, unskilled labor, and land as inputs, and an industrial technology that only uses the two types of labor. Production in each sector is carried out by competitive firms. The main task of the technology setup is to deliver an industrial revolution from stagnation to growth: the takeoff takes place once the industrial technology becomes sufficiently productive to be introduced alongside agriculture.

The firm-level industrial production function exhibits constant returns to scale, and is given by:

$$
y_{I}=A_{I}\left(l_{S}\right)^{1-\alpha}\left(l_{U}\right)^{\alpha},
$$

where $y_{I}$ is output ( $I$ stands for "Industry"), $A_{I}$ is a productivity parameter, $l_{S}$ and $l_{U}$ are inputs of skilled and unskilled labor, and the parameter $\alpha$ satisfies $0<\alpha<1$. Since there are no externalities, aggregate industrial output is $Y_{I}=A_{I}\left(L_{I S}\right)^{1-\alpha}\left(L_{I U}\right)^{\alpha}$, where $L_{I S}$ and $L_{I U}$ are the aggregate amounts of skilled and unskilled labor employed in the industrial sector. Since I want to abstract from bequests, there is no capital in the production function. The setup is equivalent, however, to a model with capital under the 
small-open-economy assumption, which is the approach taken by Galor and Weil (2000). ${ }^{8}$ The agricultural sector uses the two types of labor and land. The aggregate agricultural production function is given by:

$$
Y_{F}=A_{F}\left(L_{F S}\right)^{\theta_{S}}\left(L_{F U}\right)^{\theta_{U}}(Z)^{1-\theta_{S}-\theta_{U}} .
$$

Here $Y_{F}$ is agricultural output ( $F$ stands for "Farm"), $A_{F}$ is a productivity parameter, $L_{F S}$ and $L_{F U}$ are the aggregate amounts of skilled and unskilled labor employed in the agricultural sector, and $Z$ is the total amount of land. I assume that the parameters satisfy $\theta_{S}, \theta_{U}>0$ and $\theta_{S}+\theta_{U}<1$.

To abstract from land ownership and bequests, I assume that land is a public good. From the perspective of a small individual firm operating the agricultural technology, there are constant returns to labor. However, since there is a limited amount of land, labor input by one firm imposes a negative externality on all other firms. On the level of an individual firm, for given labor inputs $l_{S}$ and $l_{U}$ of skilled and unskilled labor output $y_{F}$ is given by:

$$
y_{F}=\tilde{A}_{F}\left(l_{S}\right)^{\frac{\theta_{S}}{\theta^{+\theta_{U}}}}\left(l_{U}\right)^{\frac{\theta_{U}}{\theta_{S}+\theta_{U}}}
$$

where:

$$
\tilde{A}_{F}=A_{F}\left[\left(L_{F S}\right)^{\theta_{S}}\left(L_{F U}\right)^{\theta_{U}}\right]^{-\frac{1-\theta_{S}-\theta_{U}}{\theta_{S} \theta_{U}}}(Z)^{1-\theta_{S}-\theta_{U}} .
$$

Thus the total amount of labor employed has a negative effect on the productivity of an individual firm. The specific form of the external effect was chosen such that the individual production functions (3) aggregate to (2) above. As far as the analysis in this paper is concerned, the main feature of the agricultural production function is decreasing returns to labor. The assumption of decreasing returns is essential for generating the Malthusian regime. ${ }^{9}$ I assume that the industrial sector is more skill-intensive than the agricultural

\footnotetext{
${ }^{8}$ Specifically, if the industrial production function is $y=B\left[\left(l_{S}\right)^{1-\alpha}\left(l_{U}\right)^{\alpha}\right]^{1-a} k^{a}$ and the fixed return on capital $k$ is given by $r$, capital adjusts such that its marginal product is equal to $r$. Solving that condition for $k$ gives $k=(a B / r)^{1 /(1-a)}\left(l_{S}\right)^{1-\alpha}\left(l_{U}\right)^{\alpha}$, and plugging this back into the production function gives:

$$
y=B^{\frac{1}{1-a}}(a / r)^{\frac{a}{1-a}} l_{S}^{1-\alpha} l_{U}^{\alpha}
$$

which is (1) by setting $A_{I}=B^{\frac{1}{1-a}}(a / r)^{\frac{a}{1-a}}$. The same argument applies to the agricultural production function.

${ }^{9}$ The assumption of an external effect from labor, on the other hand, is not essential, and is used only to abstract from land ownership. The model is equivalent to a setup in which all land is owned by foreigners or a separate land-owning class.
} 
sector:

Assumption 1 The industrial sector is more skill-intensive, i.e., the production function parameters satisfy $\alpha<\theta_{U}$, which implies $1-\alpha>\theta_{S}$.

This assumption will be important for generating fertility decline during the transition to the growth regime. The productivities of both technologies grow at constant, though possibly different rates:

$$
A_{F}^{\prime}=\gamma_{F} A_{F}, \quad A_{I}^{\prime}=\gamma_{I} A_{I},
$$

where $\gamma_{F}, \gamma_{I}>1$. The assumption of exogenous and constant productivity growth is made to emphasize that the specific source of productivity improvements does not matter for the qualitative results of the model; it is only necessary that productivity growth takes place at all. Neither is it necessary to assume a change in the rate of productivity growth to explain the switch from stagnation to growth. Exogenous productivity growth allows us to apply the model equally to countries at the technology frontier (such as England in the 19th century) and to countries which mostly adopt existing technology (such as Korea and Brazil in the 20th century).

The state vector $x$ in this economy consists of the productivity levels $A_{F}$ and $A_{I}$ in the agricultural and industrial sectors, and the measures $N_{S}$ and $N_{U}$ of skilled and unskilled adults: $x \equiv\left\{A_{F}, A_{I}, N_{S}, N_{U}\right\}$ The only restriction on the state vector is that it has to consist of nonnegative numbers. Therefore the state space $X$ for this economy is given by $X \equiv \mathbf{R}_{+}^{4}$.

In equilibrium, wages are a function of the state. It will be shown in Proposition 1 below that firms will always be operating in the agricultural sector, while the industrial sector is only operated if the wages satisfy the condition $w_{S}(x)^{1-\alpha} w_{U}(x)^{\alpha} \leq A_{I}(1-\alpha)^{1-\alpha} \alpha^{\alpha}$. The problem of a firm in sector $j$, where $j \in\{F, I\}$, is to maximize profits subject to the production function, taking wages as given. Profit maximization implies that wages equal marginal products in each sector. Writing labor demand as a function of the state, for the agricultural sector we get the following conditions:

$$
\begin{aligned}
& w_{S}(x)=A_{F} \frac{\theta_{S}}{\theta_{S}+\theta_{U}} \frac{L_{F U}(x)^{\theta_{U}}}{L_{F S}(x)^{1-\theta_{S}}} Z^{1-\theta_{S}-\theta_{U}}, \\
& w_{U}(x)=A_{F} \frac{\theta_{U}}{\theta_{S}+\theta_{U}} \frac{L_{F S}(x)^{\theta_{S}}}{L_{F U}(x)^{1-\theta_{U}}} Z^{1-\theta_{S}-\theta_{U}} .
\end{aligned}
$$


If the industrial sector is operating, wages have to equal marginal products as well:

$$
\begin{array}{lll}
w_{S}(x)=A_{I}(1-\alpha)\left(\frac{L_{I U}(x)}{L_{I S}(x)}\right)^{\alpha} & \text { if } & L_{I S}(x), L_{I U}(x)>0, \\
w_{U}(x)=A_{I} \alpha\left(\frac{L_{I S}(x)}{L_{I U}(x)}\right)^{1-\alpha} & \text { if } & L_{I S}(x), L_{I U}(x)>0 .
\end{array}
$$

Instead of writing out the firms' problem in the definition of an equilibrium below, I will impose (5)-(8) as equilibrium conditions.

\section{Preferences and Policies}

I will now turn to the decision problem of the adults. Adults care about consumption and the number and utility of their children. The preference structure is an extension of Becker and Barro (1988) to the case of different types of children. The main objective of the preference setup is to generate a quantity-quality tradeoff between the number of children and education per child. This tradeoff is essential for educational and child-labor policies to have an effect.

Adults discount the utility of their children, and the discount factor is decreasing in the number of children. In other words, the more children an adult already has, the smaller is the additional utility from another child. The utility of an adult who consumes $c$ units of the consumption good and has $n_{S}$ skilled and $n_{U}$ unskilled children is given by:

$$
c^{\sigma}+\beta\left(n_{S}+n_{U}\right)^{-\epsilon}\left[n_{S} V_{S}^{\prime}+n_{U} V_{U}^{\prime}\right],
$$

and I assume $0<\beta<1,0<\sigma<1$, and $0<\epsilon<1$. $V_{S}^{\prime}$ is the utility skilled children will enjoy as adults, and $V_{U}^{\prime}$ is the utility of unskilled children, both foreseen perfectly by the parent. The parameter $\sigma$ determines the elasticity of utility with respect to consumption, $\beta$ is the general level of altruism, and $\epsilon$ is the elasticity of altruism with respect to the number of children. The utilities $V_{S}^{\prime}$ and $V_{U}^{\prime}$ are outside of the control of parents and are therefore taken as given. The utility of children depends on the aggregate state vector in the next period, and since there is a continuum of people, aggregates cannot be influenced by any finite number of people.

Adults are endowed with one unit of time, and they allocate their time between working and child-raising. Children are costly, both in terms of goods and in terms of time. Raising each child takes $\rho>0$ units of the consumption good and a fraction $\phi>0$ of the total 
time available to an adult. Adults also have to decide on the education of their children. Children need a skilled teacher to become skilled. It takes a fraction $\phi_{S}$ of a skilled adult's time to teach one child. Therefore, if parents want skilled children, they have to send their children to school and pay the skilled teacher. Children who do not go to school stay unskilled and work during childhood. Children can perform only the unskilled task, and one working child supplies $\phi_{U}$ units of unskilled labor. The parameter $\phi_{U}$ is smaller than one since children do not work from birth on, and since they are not as productive as adults. I also assume $\phi_{U}<\phi$, so that even after accounting for child labor there is still a net cost associated with having unskilled children.

There are two government policies in the model, a child-labor restriction and an education subsidy. With these policies, the government can influence both components of the opportunity cost of education for a child: the value of a child's time in terms of child labor, and the direct schooling cost. A child-labor restriction amounts to lowering the parameter $\phi_{U}$. The government chooses a function $\phi_{U}(\cdot)$ which determines how much time children work, depending on the state. Since restrictions can only lower the legal amount of child labor, I require $0 \leq \phi_{U}(x) \leq \phi_{U}$ for all $x .{ }^{10}$ The government also has the option of subsidizing a fixed amount of the schooling cost for all children at school. This expenditure is financed with a flat income tax, and budget balance is observed in every period. The government chooses a function $\delta$ that determines the fraction of the schooling cost to be paid by the government, where $0 \leq \delta(x) \leq 1$ for all $x$. Contingent on this function, the flat $\operatorname{tax} \tau$ is chosen to observe budget balance.

With taxes and the subsidy, the budget constraint of an adult of type $i$ is given by:

$$
\begin{aligned}
& c+\rho\left(n_{S}+n_{U}\right)+(1-\delta(x)) \phi_{S} w_{S}(x) n_{S} \\
& \quad \leq(1-\tau(x))\left[\left(1-\phi\left(n_{S}+n_{U}\right)\right) w_{i}(x)+\phi_{U}(x) w_{U}(x) n_{U}\right] .
\end{aligned}
$$

The right-hand side is after-tax income of the adult plus the income from sending unskilled children to work. Notice that the time cost $\phi$ for each child has to be subtracted from the time endowment to compute labor supply. On the left-hand side are consumption, the goods cost for each child, and the part of the education cost for the skilled children that is paid by the parents. For simplicity, adults are not restricted to choose integer numbers of children. Also notice that there is no uncertainty in this model. Whether a child becomes skilled does not depend on chance or unobserved abilities, but is under

\footnotetext{
${ }^{10}$ In the applications below, I will consider a one-time change in child labor policy.
} 
full control of the parent.

In equilibrium, the wages and the utilities of skilled and unskilled people are functions of the state vector. The maximization problem of an adult of type $i$, where $i \in\{S, U\}$, is described by the following Bellman equation:

$$
V_{i}(x)=\max _{c, n_{U}, n_{S} \geq 0}\left\{c^{\sigma}+\beta\left(n_{S}+n_{U}\right)^{-\epsilon}\left[n_{S} V_{S}\left(x^{\prime}\right)+n_{U} V_{U}\left(x^{\prime}\right)\right]\right\}
$$

subject to the budget constraint (9) and the equilibrium law of motion $x^{\prime}=g(x)$.

For the problem of a parent always to be well defined, we have to place a joint restriction on the parameters which ensures that the effective discount factor is not higher than one. In other words, adults cannot place higher weight on the utility of their children than on their own utility. Since the discount factor depends on the number of children, we have to consider the highest possible number of children, which is reached by an unskilled adult who spends all income on children. The resulting number of children is $1 /\left(\phi-\phi_{U}\right)$.

Assumption 2 The parameters $\beta, \epsilon, \sigma, \phi, \phi_{U}$, and $\gamma_{I}$ satisfy:

$$
\beta\left(\gamma_{I}\right)^{\sigma}\left(\frac{1}{\phi-\phi_{U}}\right)^{1-\epsilon}<1 .
$$

Here $\left(\gamma_{I}\right)^{\sigma}$ is the growth rate of utility along the balanced growth path which is reached after the switch to the industrial technology.

The fact that only parents, not children, make educational decisions leads to a market imperfection. With perfect markets, children would be able to borrow funds to finance their own education. In equilibrium, children would have to be indifferent between going to school or not, so that net income of skilled and unskilled adults would be equalized. Since there are no differences in ability or stochastic income shocks, the market imperfection is necessary to create inequality in this model. I also rule out the possibility that parents write contracts that bind their children. Otherwise, parents could borrow funds from richer adults, and have their children pay back the loan to the children of the lender. It will be shown in Section 3 below that the adults' problem has only corner solutions. Adults either send all their children to school, or none of them; there are never both skilled and unskilled children within the same family. It is possible, however, that adults of a specific type are just indifferent between sending all their children to school or none. 
In that case, some parents of a given type might decide to have skilled children, while others go for the unskilled variety. In equilibrium, the typical situation will be that all skilled parents have skilled children, while there are both unskilled parents with unskilled children and unskilled parents who send their children to school. In other words, there is upward intergenerational mobility.

In the definition of an equilibrium I have to keep track of the fractions of adults of each type who have skilled and unskilled children. The function $\lambda_{i \rightarrow j}(\cdot)$ gives the fraction of adults of type $i$ who have children of type $j$, as a function of the state $x$. For each type of parent and for all $x \in X$ these fractions have to sum to one:

$$
\lambda_{S \rightarrow S}(x)+\lambda_{S \rightarrow U}(x)=\lambda_{U \rightarrow S}(x)+\lambda_{U \rightarrow U}(x)=1 .
$$

The policy function $n_{j}(i, \cdot)$ gives the number of children for $i$-type parents who have $j$ type children as a function of the state.

The remaining equilibrium conditions are the labor-market clearing constraints, the budget constraint of the government, and the laws of motion for the number of skilled and unskilled adults. These constraints and a formal definition of an equilibrium are given in Appendix A.

\section{Analytical Results}

This section derives a number of theoretical results that will be useful for describing the equilibrium behavior of the model. First, I analyze the two production sectors, and then I turn to the decision problem of an adult in the economy. All proofs are contained in the appendix.

On the technology side the main result is that while the agricultural sector is always operating, industrial firms produce only if industrial productivity is sufficiently high relative to wages. The following propositions derive the conditions that are necessary for production in industry and agriculture.

Proposition 1 Firms will be operating in the industrial sector only if the skilled and unskilled wages $w_{S}(x)$ and $w_{U}(x)$ satisfy the condition:

$$
w_{S}(x)^{1-\alpha} w_{U}(x)^{\alpha} \leq A_{I}(1-\alpha)^{1-\alpha} \alpha^{\alpha}
$$


In the agricultural sector, firms will be operating given any wages.

It is easy to check whether the industrial sector will be operated for a given supply of skilled and unskilled labor. We can use conditions (5) and (6) to compute wages in agriculture under the assumption that there is agricultural production only. If the resulting wages satisfy condition (11), the industrial technology is used. Skilled and unskilled labor is allocated such that the wage for each skill is equalized across the two sectors. If condition (11) is violated, production takes place in agriculture only.

In equilibrium, initially only the agricultural technology is used. Given that there is positive productivity growth in industry, at some point the industrial technology becomes sufficiently productive to be introduced alongside agriculture, and an "industrial revolution" occurs. This behavior arises from an interaction between the properties of the two production sectors and the population dynamics in the model. Since population is determined by fertility decisions, I will now turn to the decision problem of an adult in the model economy.

From the point of view of an adult, the utility of a potential skilled or unskilled child is given by a number that cannot be influenced. There are no individual state variables, and the utility of children is determined by fertility decisions in the aggregate, which adults take as given since there is a continuum of people. This allows us to analyze the decision problem of an adult without solving for a complete equilibrium first. In this section, we will analyze the decision problem of an adult who receives (after-tax) wage $w>0$ and who knows that skilled children will receive utility $V_{S}>0$ in the next period, whereas unskilled children can expect $V_{U}>0$. I restrict attention to positive utilities, because if children receive zero utility, it is optimal not to have any children. In order to keep notation simple, I will express the cost of children directly in terms of the consumption good. The cost for a skilled child is $p_{S}$, and the cost for an unskilled child is denoted as $p_{U}$. For example, without government policies we have $p_{S}=\phi w+\phi_{S} w_{S}+\rho$ and $p_{U}=\phi w-\phi_{U} w_{U}+\rho$. We always have $p_{S}>p_{U}$; skilled children are more expensive than unskilled children.

We can now write the maximization problem of an adult as:

$$
\max _{n_{S}, n_{U} \geq 0}\left\{\left(w-p_{S} n_{S}-p_{U} n_{U}\right)^{\sigma}+\beta\left(n_{S}+n_{U}\right)^{-\epsilon}\left[n_{S} V_{S}+n_{U} V_{U}\right]\right\} .
$$

An alternative way of formulating this problem is to imagine the adults as choosing the total education cost $E$ they spend on raising children and the fraction $f$ of this cost that 
they spend on skilled children. The number of children is then given by $n_{S}=f E / p_{S}$ and $n_{U}=(1-f) E / p_{U}$. In this equivalent formulation, the maximization problem of the adult is:

$$
\max _{0 \leq E \leq w, 0 \leq f \leq 1}\left\{(w-E)^{\sigma}+\beta E^{1-\epsilon}\left(f / p_{S}+(1-f) / p_{U}\right)^{-\epsilon}\left[f V_{S} / p_{S}+(1-f) V_{U} / p_{U}\right]\right\} .
$$

The first result is that the decision problem of an adult has only corner solutions:

Proposition 2 For any pair $\{E, f\}$ that attains the maximum in (13) we have either $f=0$ or $f=1$.

Adults choose either skilled or unskilled children, but never mix both types in one family. We can gain intuition for this result by considering the model with $\epsilon=0$ (which is ruled out by assumption), in which case both the utility gained from having children and the cost of children are linear in the numbers of the two types of children. If we have $V_{S} / p_{S}=$ $V_{U} / p_{U}$, the adult is indifferent between unskilled and skilled children and any convex combination of the two types. However, if we now have $\epsilon>0$, as assumed, the term $\left(f / p_{S}+(1-f) / p_{U}\right)^{-\epsilon}$ in (13) becomes a convex function of $f$, and the adult will choose a corner solution.

Given that there are only corner solutions, the optimal number of children can be determined by separately computing the optimal choices assuming that there are only unskilled or only skilled children. We can then compare which type yields higher utility. Parents who decide to have children of type $i$ solve:

$$
\max _{0 \leq n_{i} \leq w / p_{i}}\left\{\left[\left(w-p_{i} n_{i}\right)\right]^{\sigma}+\beta\left(n_{i}\right)^{1-\epsilon} V_{i}\right\} .
$$

The first-order condition can be written as:

$$
\beta(1-\epsilon)\left(w-p_{i} n_{i}\right)^{1-\sigma} V_{i}=\sigma p_{i}\left(n_{i}\right)^{\epsilon} .
$$

There is a unique positive $n_{i}$ solving this equation, and the second-order condition for a maximum is satisfied given that we assume $0<\sigma<1$ and $0<\epsilon<1$. The optimal number of children $n_{i}$ is increasing in the children's utility $V_{i}$ and in the wage $w$. Thus children are a normal good in this model. On the other hand, if the cost of children $p_{i}$ is proportional to the wage $w$, the optimal number of children decreases with the wage. Thus if the cost of children is a pure time cost, the substitution effect outweighs the income effect. 
If an adult is indifferent between skilled and unskilled children, the total expenditure on children does not depend on the type of the children.

Proposition 3 An adult is indifferent between skilled and unskilled children if and only if the costs and utilities of children satisfy:

$$
\frac{V_{S}}{\left(p_{S}\right)^{1-\epsilon}}=\frac{V_{U}}{\left(p_{U}\right)^{1-\epsilon}} .
$$

If an adult is indifferent, the total expenditure on children does not depend on the type of children that is chosen.

Propositions 2 and 3 have implications for intergenerational mobility in the model. Proposition 3 states that for given utilities of skilled and unskilled children the ratio of the prices of skilled and unskilled children determines whether parents send their children to school. As long as the wage for skilled labor is higher than the unskilled wage, skilled children are relatively cheaper for skilled parents, since $w_{S}>w_{U}$ implies:

$$
\frac{\phi w_{S}+\phi_{S} w_{S}+\rho}{\phi w_{S}-\phi_{U} w_{U}+\rho}<\frac{\phi w_{U}+\phi_{S} w_{S}+\rho}{\phi w_{U}-\phi_{U} w_{U}+\rho} .
$$

The term on the left-hand side is the ratio of the prices for skilled and unskilled children for skilled adults, and the right-hand side is the ratio for unskilled adults. The cost of time is higher for skilled adults, because the skilled wage is higher than the unskilled wage. Since the opportunity cost of child rearing makes up a larger fraction of the cost of unskilled children, unskilled children are relatively more expensive for skilled parents.

Since the relative price of skilled and unskilled children differs for skilled and unskilled parents, it cannot be the case that both types of adults are indifferent between the two types of children at the same time. Since skilled children are relatively cheaper for skilled parents, in equilibrium there are always skilled parents who have skilled children. Otherwise, there would be no skilled children at all, which cannot happen in equilibrium. Likewise, there are always unskilled adults with unskilled children.

Taking these facts together, exactly three situations can arise in any given period. The first possibility is that skilled parents strictly prefer skilled children, while unskilled parents strictly prefer unskilled children. In that case, there is no intergenerational mobility. The second possibility is that skilled parents are indifferent between the two types of children, while all unskilled parents have unskilled children. The third option is that all skilled 
parents have skilled children, while the unskilled adults are indifferent between the two types. This last case is the typical one along an equilibrium path, as will be explained in more detail later. In this situation, there is upward intergenerational mobility, because some unskilled adults have skilled children, but no downward mobility.

The following proposition sums up the implications of these results for an equilibrium.

Proposition 4 In equilibrium, for any $x \in X$ such that $w_{S}(x)>w_{U}(x)$, the following must be true:

- A positive fraction of skilled adults has skilled children, and a positive fraction of unskilled adults has unskilled children:

$$
\lambda_{S \rightarrow S}(x), \lambda_{U \rightarrow U}(x)>0 .
$$

- Just one type of adult can be indifferent between the two types of children:

$$
\begin{aligned}
& \lambda_{S \rightarrow U}(x)>0 \text { implies } \lambda_{U \rightarrow S}(x)=0, \\
& \lambda_{U \rightarrow S}(x)>0 \text { implies } \lambda_{S \rightarrow U}(x)=0 .
\end{aligned}
$$

- Specifically, $\lambda_{S \rightarrow U}(x)>0$ implies:

$$
\left(\frac{\phi w_{S}(x)+\phi_{S} w_{S}(x)+\rho}{\phi w_{S}(x)-\phi_{U} w_{U}(x)+\rho}\right)^{1-\epsilon}=\frac{V_{S}(g(x))}{V_{U}(g(x))}
$$

and $\lambda_{U \rightarrow S}(x)>0$ implies:

$$
\left(\frac{\phi w_{U}(x)+\phi_{S} w_{S}(x)+\rho}{\phi w_{U}(x)-\phi_{U} w_{U}(x)+\rho}\right)^{1-\epsilon}=\frac{V_{S}(g(x))}{V_{U}(g(x))} .
$$

\section{Outline of the Behavior of the Model}

Assuming that the economy starts at a time when productivity in industry is low compared to agriculture, the economy evolves through three different regimes: The Malthusian regime, the transition, and the growth regime. In the Malthusian regime the industrial technology is too inefficient to be used for some time. Therefore the model behaves 
like one in which there is an agricultural sector only. The economy displays Malthusian features-wages stagnate, and population growth offsets any improvements in productivity.

There are three key features of the model that generate the Malthusian regime. First, it is essential that children are a normal good. This property ensures that population growth increases once improvements in technology lead to higher wages. The second necessary assumption is that the agricultural technology exhibits decreasing returns to the size of the labor force. This feature ensures that higher population growth depresses wages, which pushes the economy back to the steady state. The third key assumption is that there is a goods cost $\rho$ for each child. Without this cost, it would be possible that population growth stays ahead of productivity growth, and wages converge to zero. Taken together, these features create a Malthusian feedback in which rising wages raise population growth, but population growth depresses wages, resulting in a steady state in which wages are constant.

The values for all variables in the Malthusian regime can be determined by solving a system of steady-state equations under the assumption that only the agricultural technology is used. For a wide range of parameter choices, there is a solution to the steady-state equations in which both wages and the ratio of skilled to unskilled adults are constant ${ }^{11}$. In the steady state, average fertility is higher for unskilled adults. While all skilled adults send their children to school, there are some unskilled parents with unskilled children and others with skilled children. Wages depend on preference parameters and the growth rate of agricultural productivity, but are independent of the level of productivity, since productivity growth is exactly offset by population growth.

Even though only the agricultural production function is used in the Malthusian regime, the productivity of the industrial technology is increasing over time. At some point, productivity in industry reaches a level at which industrial production is profitable at the wages that prevail in the Malthusian regime. From that time on the industrial technology will be used alongside the agricultural technology. Since population growth does not depress wages in industry, wages and income per capita start to grow with productivity in the industrial sector. While the model assumes that the growth rate of productivity in industry is constant even before the technology is used, all that is necessary is that pro-

\footnotetext{
${ }^{11}$ If the schooling cost is very high, it is possible that no solution exists and the fraction of skilled adults converges to zero. Also, if productivity growth and the cost of children are very high it is possible that population growth is not high enough to offset productivity growth. Neither case arises in the calibrated model.
} 
ductivity growth in industry is bounded away from zero. This is a natural assumption since technology in industry and agriculture is complementary, in the sense that inventions which are useful for agriculture also have industrial uses. For example, James Watt's contributions to the design of steam engines would not have been possible without prior discoveries in mechanics and metallurgy that were originally aimed at improving agricultural (and perhaps military) technology.

The evolution of fertility and the income distribution once the transition starts depends on the specific properties of the industrial production function. Given Assumption 1 (production in industry is more skill-intensive than production in agriculture), the introduction of the industrial technology increases the wage premium for skilled labor. This increases the returns to education, so that more unskilled adults will choose to have skilled children, resulting in higher social mobility. The overall effect on fertility is uncertain. The increased demand for expensive skilled children would tend to lower fertility, but then since wages start to grow, the utility of children relative to their parents increases, which tends to increase fertility. The transition can be influenced by public policy. Both an education subsidy and child-labor restrictions lower the relative cost of skilled children, so that both policies have a positive effect on the number of children going to school. The effects on fertility, however, are different. Since a subsidy lowers the cost of children, an education subsidy tends to increase fertility, even though more children are going to school. Child labor restrictions, on the other hand, increase the cost of children, and therefore lead to lower fertility. The quantitative importance of public policies during the transition will be assessed below.

If productivity growth in industry is sufficiently high, the fraction of output produced in industry will increase over time, until the agricultural sector ultimately becomes negligible. The economy will then reach a balanced growth path, the growth regime. Here the model behaves like one in which there is the industrial technology only. All variables can be computed by solving a system of balanced-growth equations. Whether fertility is higher in the growth regime than in the Malthusian regime is determined by the relative importance of skill in the two technologies. If the industrial technology is sufficiently skill-intensive, in the growth regime most children will go to school. Since schooling is costly, this will tend to lower fertility and population growth. On the other hand, as wages grow, the physical cost $\rho$ of children ultimately becomes negligible. This effect makes children relatively cheaper in the growth regime, which will tend to increase fertility. Unless the schooling cost is very high, the ratio of skilled to unskilled adults reaches 
a fixed number in the growth regime. ${ }^{12}$ Population growth and fertility are constant, and wages and consumption grow at the rate of technical progress. Average fertility is lower for skilled than for unskilled adults. This would be true even if the schooling cost were zero and if there were no child labor, since then the only remaining cost of children would be a time cost. It was shown in Section 3 that if there is a pure time cost for having children, wages and fertility are negatively related. With positive schooling cost and child labor the relative cost of skilled children increases, and since relatively more skilled adults have skilled children, this will further increase the fertility differential between the two types of adults. Given that fertility is higher for unskilled adults in the balanced growth path, it has to be the case that some unskilled adults have skilled children. Otherwise the fraction of unskilled adults would increase over time. Therefore unskilled adults are just indifferent between the two types of children.

In the limit-economy without agriculture wages are determined by the ratio of skilled to unskilled labor supply. The only required state variables are therefore the ratio of skilled and unskilled adults and the productivity level in industry. The setup can further be simplified by noting that the period utility function is of the constant-elasticity form, and that wages are linear in the productivity level. This results in value functions that are homogeneous in the industrial productivity level:

$$
V_{i}\left(A_{I}, N_{S} / N_{U}\right)=A_{I}^{\sigma} V_{i}\left(N_{S} / N_{U}\right)
$$

This reduces the growth regime essentially to a one-dimensional system, with the ratio of skilled to unskilled adults as the state variable.

I will now turn to the question whether public policy can have large effects during the transition. In the following sections, I calibrate the model parameters, and simulate the model under different assumptions on policies.

\section{Calibration}

In this section I describe the procedure for calibrating the model parameters. Since I use the model to examine whether policy differences across countries can account for different transition experiences, it would be counterproductive to choose parameters to

\footnotetext{
${ }^{12}$ If the schooling cost is too high, the number of skilled adults converges to zero over time.
} 
closely match data from one specific country. Rather, I choose parameters such that in the growth regime the model matches certain features of modern industrialized countries, while in the Malthusian regime the model resembles a pre-modern economy. For the growth regime, I use current U.S. data, while for the pre-modern economy I rely mostly on England, where the available data is of relatively high quality. Since the calibration procedure pins down only the two ends of the time line, we can use the transition period for testing the model.

I start by describing the parameter choices that are determined by features of the growth regime. The parameter $\gamma_{I}$, the rate of technological progress in the industrial sector, determines the growth rate of per-capita output in the growth regime. In the United States, real GDP per capita increased on average by $1.9 \%$ per year in the period from 1960 to 1992. I therefore chose the yearly growth rate of productivity in the industrial sector to be $2 \%$. Since a model period is 25 years, this gives a value for $\gamma_{I}$ of 1.64 .

Given that there are strict compulsory schooling laws and child-labor restrictions in the U.S., the parameters for the growth regime are calibrated under the assumption that child labor is ruled out. The schooling cost parameter $\phi_{S}$ determines the number of teachers and the student-teacher ratio in the growth regime. According to the Digest of Education Statistics (U.S. Department of Education, 1998), in the U.S. teachers on all levels of education make up $1.5 \%$ of the American population, and there are about 16 students per teacher. Since, unlike in the model, in the real world each teacher teaches more than one generation of students, we cannot match both values at the same time. If the ratio of teachers to population is matched, class sizes would be too big, and if class size is matched, there would be too many teachers. As a compromise, I chose $\phi_{S}$ to be 0.04 , which results in a class size of 21 , and $1.7 \%$ of the population are teachers. ${ }^{13}$ The time cost $\phi$ was then chosen to match the total expenditure on children in the United States, estimated for 1992 by Haveman and Wolfe (1995). According to their estimates, parental per-child expenditures were $\$ 9,200$ or about $38 \%$ of per capita GDP. I chose $\phi$ to be 0.155 , which leads to the same ratio of per-child expenditures to GDP per capita. Knowles (1999) calibrates the same parameter to other estimates of the cost of children and arrives at a similar value of 0.15 .

Using data from 1975, Jones (1982) finds that in Britain the difference in total fertility between women with elementary education or less and women with secondary or higher education is about 0.4 , and the corresponding value for the U.S. is about 0.5 . I chose the

\footnotetext{
${ }^{13}$ Variations of the model which match either statistic exactly lead to essentially the same outcomes.
} 
preference parameters $\sigma, \epsilon$ and $\beta$ to be consistent with a fertility differential of 0.5 between skilled parents and unskilled parents who have unskilled children, and a total fertility rate of 2.0, which matches current fertility in the United States. The choices $\sigma=0.5, \epsilon=0.5$, and $\beta=0.132$ are consistent with these observations.

According the Digest of Education Statistics, in 1994 total expenditures on education were $7.3 \%$ of GDP, while public expenditures were $4.8 \%$, or roughly two thirds of the total. These numbers exclude expenditures by parents and students, like textbooks and transportation. The government therefore pays for less than two thirds of all educational expenditures. In the model, I chose the fraction $\delta$ of education cost paid for by the government to be 0.5 .

The technology parameter $\alpha$, the share of unskilled labor in the industrial production function, mainly determines the ratio of skilled to unskilled people in the growth regime. It is hard to match this ratio to data, since there are more than two skill levels in the real world. If we define skill to mean completed high school, skilled people would make up most of the population, since already today almost $90 \%$ of recent school cohorts satisfy this criterion. On the other hand, if skilled means completed college education, the number of skilled people would drop below $30 \%$. Since college education was rare in some of the countries and time periods I am interested in, I chose a compromise with higher weight on high school. The parameter $\alpha$ was chosen to be .22, which results in $75 \%$ of the population in the growth regime to be skilled.

I now turn to the Malthusian regime. Most parameters are identical to the growth regime, we only need to calibrate the agricultural technology and the child-labor parameter. The parameter $\gamma_{F}$, the rate of technological progress in the agricultural sector, determines fertility in the Malthusian regime. In Britain the total fertility rate was about 4.0 in 1700, and values in other European countries were similar. The value $\gamma_{F}=1.32$ yields this fertility rate in the Malthusian regime. The fixed cost for children $\rho$ is a scale parameter and can be chosen arbitrarily. I chose $\rho=.001$.

The child-labor parameter $\phi_{U}$ is hard to calibrate, since there is only limited evidence on the extent of child labor before the industrial revolution. However, $\phi_{U}$ has to be chosen sufficiently large to allow a Malthusian regime. If $\phi_{U}$ is small, population growth does not catch up with technological progress, and per capita output grows already before the introduction of the industrial technology. On the other hand, if $\phi_{U}$ is too large, the number of skilled agents converges to zero after the industrial technology is introduced. My choice of $\phi_{U}=.07$ is in the middle ground and is consistent both with Malthusian 
stagnation and a growth regime with a positive fraction of skilled agents. Adjusting for labor supply, this implies that nine children are equivalent to one unskilled worker. The behavior of the model is sensitive to the choice of $\phi_{U}$; by making $\phi_{U}$ large, we can increase the effects of eliminating child labor. It is therefore important to ascertain that $\phi_{U}$ is not unrealistically large. From the perspective of the parent, the key question is how much of household income is contributed by children. Horrell and Humphries (1995) find that in a sample of working-class families in England around 1800 children contributed between $27 \%$ and $32 \%$ of household income, whereas in the model income from child labor makes up only $25 \%$ of income in families with working children.

For the parameters of the agricultural technology, I chose $\theta_{S}=.1$ and $\theta_{U}=.5$. With these choices, the share of output going to land rents is $40 \%$, and skilled adults make up about $5 \%$ of the population in the Malthusian regime. A lower bound on the land share can be derived from the English National Accounts for 1688 in Deane and Cole (1969). At that time rents made up $27 \%$ of national income. Since some of the $34 \%$ of national income going to non-rent property income and profits are also derived from land, 30\% is a reasonable lower bound for the share of land. On the other hand, share-cropping contracts typically allocated $50 \%$ of output to the land owner. Since not all of national income was derived from agriculture, $50 \%$ is then an upper bound for the land share. My choice lies in the middle between these bounds.

\section{Computational Experiments}

This section uses the calibrated model to determine whether policy changes can have large effects during the transition. I simulate the model under three different assumptions on government policies, roughly corresponding to the cases of Brazil, Korea and England mentioned earlier. ${ }^{14}$ In the stylized Brazilian policy, there is no policy reform. Parents pay for education, and child labor is unrestricted. In the stylized Korean policy, the economy starts out with the same policies. Once the economy starts to leave the Malthusian regime, however, there is an immediate switch to the policies that were the basis for calibrating the growth regime. Under these policies, the government pays for $50 \%$ of the education cost for skilled children, and child labor is ruled out. While in the

\footnotetext{
${ }^{14}$ See Appendix $C$ for a description of actual policies in these countries. The policies used in the simulations are not intended to be exact copies of real-world policies. Rather, I use stylized, one-time policy changes to assess the role of educational policies in general. Especially for Brazil, the policy description in the model is not "fair" for more recent years: support for education has increased in the last decades (and fertility has been falling faster).
} 
Korean policy the reform takes place immediately once the industrial technology is introduced, in the stylized English policy the same reforms are carried out with a delay of three periods (or 75 years) after the beginning of the transition. All economies start from identical conditions. The initial values for agricultural productivity and the number of skilled and unskilled adults are chosen to start the economies in the Malthusian steady state. The productivity in industry is chosen such that the transition starts two periods after the start of the simulation. Apart from the different timing of policy reforms (no reform under the Brazilian policy, immediate reform under the Korean policy, delayed reform under the English policy), all simulations are identical.

The outcomes can be summarized as follows. The timing of policy reforms has a major impact on the timing and speed of the fertility transition. Without a policy reform, the decrease in fertility during the transition to growth is small. When a reform is introduced, it causes an immediate drop in fertility, and the transition to replacement fertility is completed within two generations after the reform. In addition, lowering the opportunity cost of education increases growth in GDP per capita, since the fraction of skilled workers in the population increases. Out of the two policies considered, child-labor restrictions account for the bulk of the results, while the effects of education subsidies are comparatively small. The same policy reforms also have a major impact on the evolution of the income distribution. As long as no policies are introduced, inequality rises during the transition, since the skill premium goes up. Once the policy reform lowers the opportunity cost of education, however, the fraction of skilled workers increases over time, which lowers the skill premium and overall inequality.

Figure 2 shows the simulated path for GDP per capita and the total fertility rate under the different policies. In the graphs for the Korean and English policies, the Brazilian outcomes are included (with dashed lines) as the benchmark case to facilitate comparisons. The time axis is labeled such that each model period corresponds to 25 years, and the start of the transition to the growth regime is placed in the year 1950 for the Brazilian and Korean policies, and in 1800 for the English policy. GDP per capita is initially constant, since the simulation starts in the Malthusian regime where wages are constant. Once the industrial technology is introduced, incomes start to grow.

The total fertility rate increases slightly before the start of the transition, and then declines in all simulations. The speed and timing of fertility decline, however, varies across the simulations. With no reform, fertility decreases only slowly to a total fertility rate of about 3. With an immediate reform, the total fertility rate drops below 3 already at the start of 
the transition, and replacement fertility is reached in less than two generations after the take-off. The maximum difference in fertility across the Brazilian and Korean simulation in any year is about 1.5 , or about $60 \%$ of the maximum difference between Korean and Brazilian data in Figure 1. Thus, while the model does not account for all of the observed differential, the effect of the policies is substantial. With the delayed policy reform of the English simulation, fertility decline starts right after the beginning of the transition as well, but speeds up after the reforms are carried out (1875 in the simulation). Relative to the actual English experience, the model with a delayed education reform does a good job in accounting for the rapid fertility decline around the end of the 19th century. The main deviation between model and data is that the model not reproduce the initial increase in fertility between 1700 and 1820 in England, as well as the peak fertility level of about 6.0 in Korea and Brazil. Across all policy options, the maximum fertility level reached in the simulations is 4.8 .

Since fertility and education decisions interact, the same policies that affect the speed of fertility decline also influence economic growth in the model. The highest growth rate is achieved under the Korean policy of an immediate education reform. Under the Korean policy, the average growth rate of GDP per capita between 1950 and 2000 is $4.2 \%$, which compares to a growth rate of only 3.3\% under the Brazilian Policy. In the data, we also observe that Korea, as well as other countries with a fast demographic transition, experienced faster growth in GDP per capita than slow-transition countries like Brazil. According to the Penn World Tables, the average growth rate in GDP per capita between 1960 and 1990 was $6.7 \%$ in Korea, but only 2.8\% in Brazil. Even if we consider the shorter period from 1960 to 1980 (which excludes the Latin American debt crisis in the 1980s), average growth was $6.2 \%$ in Korea versus $4.4 \%$ in Brazil. The growth rate differential in the data is larger than the differential in the model, which suggests that social policies and education decisions are not the only factor explaining the relative performance of Brazil and Korea. Given that the two countries are different along a number of dimensions, it would in fact be very surprising if the policies considered here were the main explanation for differences in economic performance. Nevertheless, the results suggest that the policies and their effects on fertility and education decisions are an important part of the overall explanation.

The reason for the growth-rate differential in the model is is that with education subsidies and child-labor restrictions, the skilled fraction of the population increases fast, which 
raises output since the industrial technology is skill-intensive. ${ }^{15}$ Under the Korean policy, the fraction of skilled adults in the population increases from 5\% in 1950 to almost 70\% in 2000. Under the Brazilian policy, the increase is from $5 \%$ to only about $33 \%$. In the data, we observe large differences in average skill between Korea and Brazil as well. In Korea, average years of schooling of the population aged 25 and over increased from 3.2 in 1960 to 7.8 in 1985. In Brazil, the increase was from 2.6 in 1960 to only 3.5 in 1985. Notice that of the three channels through which the speed of fertility decline affects GDP per capita only the human-capital channel is present in the model. This channel captures that because of the quantity-quality tradeoff, parents increase the education of their children when fertility falls. The model abstracts from the capital-dilution channel (lower population growth increases the capital stock per worker) and the cohort-size channel (rapid fertility decline lowers the dependency ratio). If we extended the model to capture these effects as well, the predicted growth differential would be even greater.

Apart from influencing fertility and output, policy changes also affect the income distribution. The graphs on the left-hand side of Figure 3 shows income Gini coefficients for the simulations. In the model, inequality is determined by the skill premium, which in turn depends on the relative supply of skilled and unskilled labor. The Korean policy increases the relative number of skilled adults, which offsets the increased demand for skilled labor in the industrial sector. Therefore, in the simulation with an immediate policy reform inequality is generally low and decreases slightly during the transition. The initial increase in the Gini at the time of the policy reform occurs since the demand for education suddenly increases. This temporarily raises the skill premium, because teachers are skilled. In the Brazilian simulation unskilled adults continue to make up the majority of the population. The increased demand for skill in the industry translates into an increased wage premium, so that inequality increases during the transition. With a delayed policy reform, inequality first increases, then decreases during the transition.

Thus only with the English policy do we observe the pronounced inverse-U-shaped relationship between income and inequality known as the Kuznets curve. In the real world, this pattern of inequality over the course of development was observed in the countries that industrialized first (Kuznets (1955) looked at England, Germany, and the United States), but for countries that started to grow more recently the evidence is mixed. Specifically, neither Korea nor Brazil exhibit a Kuznets curve. In Korea inequality was generally

\footnotetext{
${ }^{15}$ Because productivity growth is exogenous, the effect on growth rates is transitory, but there is a permanent level effect as long as policies differ.
} 
low, and there was little change in the income distribution over time. Between 1955 and 1985, the Gini coefficient varies between .3 and .4. In Brazil inequality was always high, with a Gini between .5 and .6. The income share going to the poorest $20 \%$ of the Korean population is about the same as the share going to the poorest $40 \%$ in Brazil. Even considering that the model abstracts from some features which are relevant for explaining the income distribution ${ }^{16}$, the results do show that interactions of public policies with fertility decisions can have large effects on the growth-inequality relationship. This may provide an explanation for why Kuznets curves show up in some countries, but not in others.

A more direct test of the distributional implications of the model would look at wage inequality, and especially the premium for skilled labor, since the skill premium is the driving force behind changes in inequality in the model. The skill premium reacts to the policies through the the general-equilibrium effect of education and fertility decisions on the relative supply of skilled and unskilled labor. Clearly, this general equilibrium effect is central to the results: fertility falls fast in the Korean simulation precisely because the policies deliver a low skill premium, which means that education is affordable even for unskilled parents. Park, Ross, and Sabot (1996) compare wage inequality in Brazil and Korea in 1976 and 1986. Consistent with the predictions of the model, they find much higher skill premia in Brazil than in Korea. Moreover, there is a substantial decline in wage inequality in Korea between 1976 and 1986. Specifically, Park, Ross, and Sabot estimate a standard earnings equation, i.e., the logarithm of earnings is regressed on education and work experience. In 1976, high school graduates in Brazil earned a 60 percent premium relative to workers who finished primary school, while the premium was only 35 percent in Korea. For university graduates, the premium (relative to primary school) was 201 percent in Brazil versus 121 percent in Korea. In 1986, the differences were even more pronounced. In Brazil, the premia for high school and university graduates were still 55 and 188 percent, respectively, while in Korea the premia had fallen to just 10 percent and 76 percent.

In the model, changes in overall fertility are driven by differences in fertility between skilled and unskilled parents. The graphs on the right-hand side of Figure 3 break down the total fertility rate in each simulation by the type of the parent. In the Brazilian simulation there are no education subsidies or child-labor restrictions. Unskilled children are

\footnotetext{
${ }^{16}$ For the comparison of Brazil and Korea, the role of land ownership is essential. After a land reform at the end of Japanese occupation, land ownership was dispersed in Korea, but always highly concentrated in Brazil. Indeed, if concentrated land ownership is introduced, the model generates high inequality with almost no time trend under the Brazilian policy.
} 
cheap relative to skilled children, and therefore unskilled parents continue to have many children throughout the transition. Initially, average fertility increases for both groups of parents, and the aggregate total fertility rate falls only because skilled adults begin to make up a larger fraction of the population. The fertility differential between skilled and unskilled parents stays large. Under the Korean policy, the fertility differential between the two types of parents declines rapidly after the policy change. The abolition of child labor and education subsidies imply that skilled children are only slightly more expensive than unskilled children, which results is a small fertility differential between skilled and unskilled parents. The same effect occurs in the English simulation after the new policies are introduced.

In the data, in line with the predictions, the available evidence shows small fertility differentials in Korea and large differentials in Brazil. According to United Nations (1995), in 1986 Brazilian women without formal education had a total fertility rate of 6.7, while for women with seven or more years of education the number is 2.4. Thus the fertility differential amounts to more than four children. Alam and Casterline (1984) report that in 1974 the total fertility rate for Korean women without formal education was 5.7, while for women with seven or more years of education the rate is 3.4. This gives a fertility differential of 2.3, roughly half of the differential in Brazil. ${ }^{17}$ England, as well as other industrialized countries, has small fertility differentials within the population today in comparison to developing countries.

In summary, we see that the policies considered have large effects on fertility decline during the transition to growth. These differences translate into further implications for GDP per capita, average education levels, fertility differentials, and the income distribution which line up well with the evidence for our examples Brazil and Korea. So far the analysis of public policy was restricted to a combination of two policies, an education subsidy and child-labor restrictions. A natural question to ask is which of the two policies is more important for generating the results described above. It turns out that the child-labor restriction has a much bigger impact than the education subsidy. Figure 4 shows outcomes for GDP per capita and fertility if either education subsidies or child labor restrictions are introduced in isolation. If only a child-labor restriction is introduced, the evolution of income per capita and fertility is similar to the Korean simulation, which introduces both policies. With a child-labor restriction there is an unambiguous increase in the cost

\footnotetext{
${ }^{17}$ Unfortunately, there is no data for Brazil and Korea for the same year. However, given the overall fall in fertility, it seems likely that the fertility differential by education in Korea was even lower in 1986 than in 1974.
} 
of unskilled children, which reduces fertility even faster compared to the case when both policies are combined. In contrast, when there is only an education subsidy, fertility actually increases initially, and the subsequent decline is much smaller than in the Korean simulation. The reason is that the education subsidy works in two different ways. Since skilled children become cheaper, more unskilled parents decide to educate their children, which lowers fertility. At the same time, however, fertility increases for the skilled parents who would have decided to educate their children even without the subsidy. The two effects are partially offsetting, and the overall impact is small. These results underline the importance of including the cost of the children's time in the opportunity cost of education. In fact, if we did not account for the cost of the children's time, it would be rather surprising that in England fertility fell fastest just at the time when free public education was introduced.

A welfare analysis of the policies is made difficult by the fact that skilled and unskilled people have opposing interests. Therefore the policies cannot be ranked using the Pareto criterion. The education subsidy, however, is beneficial for adults of both skills in the period when the subsidy is introduced. Future generations of skilled people have lower utility with the policy because of a lower skill premium. A child-labor restriction alone hurts both skills in the period when it is introduced, since the unskilled parents lose income, and the utility of skilled children falls. However, future generations of unskilled people benefit from child-labor restrictions. A combination of the two policies yields the highest growth path for GDP per capita, but future skilled generations are still better off without the policies.

\section{Conclusions}

This paper develops a theory that is consistent with a phase of stagnation during which the economy exhibits Malthusian features, followed by a transition to a growth regime. The economic transition to growth is accompanied by a demographic transition from high to low fertility. The model is used to assess whether child-labor restrictions and education subsidies can have large impacts on the fertility decline that accompanies the transition to growth.

The possibility of child labor implies that the value of a child's time becomes part of the 
opportunity cost of education. ${ }^{18}$ Without accounting for the value of the children's time, it would be very puzzling that in many countries fertility fell fastest just at the time when free public education was introduced. When there is no alternative use for a child's time, free education lowers the cost of children and therefore should lead to higher fertility. In contrast, once we account for the full opportunity cost of education including potential child labor income, educating a child is costly even if schools are free. A steep decline in fertility right after major education reforms is therefore just what we should expect to see.

Indeed, we find that education and child labor policies have large effects on the fertility transition. The policies also determine the evolution of income per capita, average education, and the income distribution of a country during the transition to growth. When comparing the two policies, the effects of education subsidies are relatively small, while accounting for child-labor regulations is crucial.

The results show that accounting for policy changes is important for understanding the experience of different countries during the transition from stagnation to growth. This finding does not rule out that other factors could play an important role as well. For example, the model abstracts from changes in mortality rates, even though declining mortality is an equally important aspect of the demographic transition as declining fertility. As a simple extension to the model, changes in child mortality can be incorporated by introducing a probability of survival until adulthood. In the calibrated model, for small increases in child mortality the number of births increases, but the number of surviving children declines. Feeding realistic survival rates into the model makes it possible to match actual fertility numbers more closely, but the effects of policy changes are still the same and dominate the effects of changing child mortality. ${ }^{19}$ In order to incorporate adult mortality, the framework would have to be extended to allow for more than two periods of life.

Another question is how the stylized policies in the model are implemented in the real world. Child-labor regulations are subject to an obvious enforcement problem, which is severe given that much child labor takes place in agriculture, where direct supervision is difficult. A number of studies have found that official child-labor restrictions do little to constrain child labor. In practice, compulsory schooling laws often appear to be a more

\footnotetext{
${ }^{18}$ The role of child labor in determining fertility has been analyzed by Rosenzweig and Evenson (1980). In line with the results here, they find that the economic contributions of children through child labor are an important determinant for fertility rates.

${ }^{19}$ Within the dynastic utility framework, changes in child mortality rates have only minor effects on fertility even if stochastic survival and sequential fertility choice are taken into account, see Doepke (2002).
} 
effective constraint on child labor than direct regulation. ${ }^{20}$ From an administrative point of view, it is easier to check that children show up in a given classroom at a certain time, as opposed to ascertaining that they do not engage in illegal work at any time and any place. Therefore, even though the policies can be used separately in the model, they are best thought of as a joint policy in practice.

In the discussion of the transition from stagnation to growth I concentrated on crosscountry differences in the fertility decline. An important question that is not addressed in this paper is why the take-off occurs at different times in different countries. The government policies that are discussed in this paper have the potential to cause a delay in the take-off of about 10 to 20 years, which is clearly too little to explain the observed differences. In order to make progress along this line, it will be necessary to move beyond the assumption of exogenous productivity growth and introduce a theory of technological progress. The results in this paper do not depend in any way on the assumption that productivity growth is exogenous. As a first step beyond exogenous growth, it is possible to link the rate of technological progress to the number of skilled people in the economy. Such a model can explain why the rate of economic growth increased during the industrial revolution, instead of jumping to the growth-regime level right away. The effects of government policies on growth would be amplified.

Going beyond the specific application to fertility decline, this paper contributes to an emerging literature which puts the spotlight on the role of policy reforms in the course of development. Every now industrialized country has introduced child labor and public education laws at a certain stage of development. The same is true about other policies such as social insurance programs. While the research in this paper suggests that policy reforms can have large effects on fertility decisions, an intriguing possibility for future research would be to examine the reverse channel. If family size is dependent on educational policies, conversely voters' preferences over such policies should depend at least partly on their earlier fertility decisions. This suggests the possibility of a two-way interaction between the demographic changes and the political reforms that characterize economies during the transition from stagnation to growth.

\footnotetext{
${ }^{20}$ For example, using U.S. data, Margo and Finegan (1996) find that child-labor restrictions are especially effective if combined with compulsory schooling laws.
} 


\section{References}

Alam, Iqbal, and J.B. Casterline. 1984. Socio-Economic Differentials in Recent Fertility. World Fertility Survey Comparative Studies No. 33. Voorburg, Netherlands: International Statistical Institute.

Barro, Robert J., and Jong-Wha Lee. 1993. International Comparisons of Educational Attainment. Journal of Monetary Economics 32:363-394.

- 1997. Schooling Quality in a Cross Section of Countries. NBER Working Paper 6198.

Becker, Gary S., and Robert J. Barro. 1988. A Reformulation of the Economic Theory of Fertility. Quarterly Journal of Economics 53(1):1-25.

Bloom, David E., and Jeffrey G. Williamson. 1998. Demographic Transitions and Economic Miracles in Emerging Asia. World Bank Economic Review 12(3):419-55.

de la Croix, David, and Matthias Doepke. 2003. Inequality and Growth: Why Differential Fertility Matters. American Economic Review 93(4):1091-1113.

Chesnais, Jean Claude. 1992. The Demographic Transition. Oxford: Oxford University Press.

Dahan, Momi, and Daniel Tsiddon. 1998. Demographic Transition, Income Distribution, and Economic Growth. Journal of Economic Growth 3:29-52.

Deane, Phyllis, and W.A. Cole. 1969. British Economic Growth 1688-1959. Cambridge: Cambridge University Press.

Deininger, Klaus, and Lyn Squire. 1996. Measuring Income Inequality: A New Database. Development Discussion Paper No. 537, Harvard Institute for International Development.

Doepke, Matthias. 2002. Child Mortality and Fertility Decline: Does the Barro-Becker Model Fit the Facts? UCLA Department of Economics Working Paper No. 824.

Fernández-Villaverde, Jesús. 2001. Was Malthus Right? Economic Growth and Population Dynamics. Mimeo, University of Pennsylvania.

Galor, Oded, and David N. Weil. 1996. The Gender Gap, Fertility, and Growth. American Economic Review 86(3):375-87.

- 2000. Population, Technology, and Growth: From Malthusian Stagnation to the Demographic Transition and Beyond. American Economic Review 90(4):806-828.

Greenwood, Jeremy, and Ananth Seshadri. 2002. The U.S. Demographic Transition. American Economic Review Papers and Proceedings 92(2):153-159.

Hansen, Gary D., and Edward C. Prescott. 2002. Malthus to Solow. American Economic Review 92(4):1205-1217.

Haveman, Robert, and Barbara Wolfe. 1995. The Determinants of Children's Attainments: 
A Review of Methods and Findings. Journal of Economic Literature 33:1829-1878.

Horrell, Sara, and Jane Humphries. 1995. The Exploitation of Little Children: Child Labor and the Family Economy in the Industrial Revolution. Explorations in Economic History 32:485-516.

International Labor Organization (ILO). Year Book of Labour Statistics. Various editions. Geneva: ILO.

Jones, Charles I. 2001. Was an Industrial Revolution Inevitable? Economic Growth over the Very Long Run. Advances in Macroeconomics 1(2): Article 1.

Jones, Elise F. 1982. Socio-Economic Differentials in Achieved Fertility. World Fertility Survey Comparative Studies No. 21. Voorburg, Netherlands: International Statistical Institute.

Kögel, Tomas, and Alexia Prskawetz. 2001. Agricultural Productivity Growth and the Escape from the Malthusian Trap. Journal of Economic Growth 6:337-57.

Knowles, John. 1999. Can Parental Decisions Explain U.S. Income Inequality? Working paper, University of Pennsylvania.

Kremer, Michael, and Daniel Chen. 1999. Income Distribution Dynamics with Endogenous Fertility. American Economic Review 89(2): 155-160.

Kuznets, Simon. 1955. Economic Growth and Income Inequality. American Economic Review 45:1-28.

Lagerlöf, Nils-Petter. 2002. Gender Equality and Long-Run Growth. Forthcoming, Journal of Economic Growth.

Maddison, Angus. 1991. Dynamic Forces in Capitalist Development: A Long-Run Comparative View. Oxford: Oxford University Press.

Margo, Robert A. and Finegan, T. Aldrich. 1996. Compulsory Schooling Legislation and School Attendance in Turn-of-the-Century America: A "Natural Experiment" Approach. Economics Letters 53:103-10.

Moav, Omer. 2001. Cheap Children and the Persistence of Poverty. CEPR Discussion Paper No. 3059.

Morand, Olivier F. 1999. Endogenous Fertility, Income Distribution, and Growth. Journal of Economic Growth 4(3):331-49.

Nardinelli, Clark. 1980. Child Labor and the Factory Acts. Journal of Economic History 40(4):739-55.

Ngai, Liwa Rachel. 2000. Barriers and the Transition to Modern Growth. Mimeo, University of Pennsylvania.

Park, Young-Bum, David R. Ross, and Richard H. Sabot. 1996. Educational Expansion and the Inequality of Pay in Brazil and Korea. In: Opportunity Forgone: Education in Brazil. Nancy Birdsall and Richard H. Sabot, edts. Inter-American Development Bank: Washington, D.C. 
Rosenzweig, Mark R., and Robert Evenson. 1977. Fertility, Schooling, and the Economic Contribution of Children in Rural India: An Econometric Analysis. Econometrica 45(5):1065-79.

Tamura, Robert. 2002. Human Capital and the Switch from Agriculture to Industry. Journal of Economic Dynamics and Control 27:207-42.

United Nations. 1995. Women's Education and Fertility Behavior. New York: United Nations.

Veloso, Fernando A. 1999. Income Composition, Endogenous Fertility and the Dynamics of Income Distribution. Mimeo, University of Chicago.

World Bank. World Tables. Various editions. Baltimore: Johns Hopkins University Press.

Wrigley, E.A., R.S. Davies, J.E. Oeppen, and R.S. Schofield. 1997. English Population History from Family Reconstitution 1580-1837. Cambridge: Cambridge University Press.

\section{A Definition of an Equilibrium}

This section introduces the remaining equilibrium conditions, starting with the determination of labor supply. Skilled adults distribute their time between working, raising and teaching their own children, and teaching children of unskilled parents. Therefore the total supply of skilled labor $L_{S}$ is given by:

$$
\begin{aligned}
L_{S}(x)=[1 & \left.-\left(\phi+\phi_{S}\right) \lambda_{S \rightarrow S}(x) n_{S}(S, x)-\phi \lambda_{S \rightarrow U}(x) n_{U}(S, x)\right] N_{S} \\
& -\phi_{S} \lambda_{U \rightarrow S}(x) n_{S}(U, x) N_{U} .
\end{aligned}
$$

Unskilled labor $L_{U}$ is supplied by unskilled adults and by children who do not go to school:

$$
\begin{aligned}
L_{U}(x)=[1 & \left.-\phi \lambda_{U \rightarrow S}(x) n_{S}(U, x)-\phi \lambda_{U \rightarrow U}(x) n_{U}(U, x)\right] N_{U} \\
& +\phi_{U}(x)\left[\lambda_{S \rightarrow U}(x) n_{U}(S, x) N_{S}+\lambda_{U \rightarrow U}(x) n_{U}(U, x) N_{U}\right] .
\end{aligned}
$$

In equilibrium, labor supply has to equal labor demand for each type of labor. I assume that skilled adults can perform both the skilled and the unskilled work, while unskilled adults can do unskilled work only. Under this assumption, the skilled wage cannot fall below the unskilled wage:

$$
w_{S}(x) \geq w_{U}(x) .
$$

The market-clearing conditions for the labor market are:

$$
\begin{aligned}
& L_{F S}(x)+L_{I S}(x) \leq L_{S}(x), \quad=\text { if } w_{S}(x)>w_{U}(x), \\
& L_{F U}(x)+L_{I U}(x)=L_{U}(x)+\left[L_{S}(x)-L_{F S}(x)-L_{I S}(x)\right] .
\end{aligned}
$$


The flat $\operatorname{tax} \tau$ which finances the education subsidy has to be chosen to observe budget balance. The correct tax rate is given by dividing the total expenditure on schooling subsidies by total wage income:

$$
\tau(x)=\frac{\delta(x) \phi_{S} N_{S}^{\prime} w_{S}(x)}{L_{S}(x) w_{S}(x)+L_{U}(x) w_{U}(x)+\phi_{S} N_{S}^{\prime} w_{S}(x)} .
$$

Here $N_{S}^{\prime}$ is the total number of skilled children. Notice that for the computation of total labor income we have to add the income of the teachers to the wage of the usual workers. Teachers receive wages for their work and are taxed like all other adults in the model economy.

The final equilibrium condition is the law of motion for population. Since I abstract from child mortality, the number of adults of a given type tomorrow is given by the number of children of that type today:

$$
\begin{aligned}
& N_{S}^{\prime}=\lambda_{S \rightarrow S}(x) n_{S}(S, x) N_{S}+\lambda_{U \rightarrow S}(x) n_{S}(U, x) N_{U}, \\
& N_{U}^{\prime}=\lambda_{S \rightarrow U}(x) n_{U}(S, x) N_{S}+\lambda_{U \rightarrow U}(x) n_{U}(U, x) N_{U} .
\end{aligned}
$$

We now have all the ingredients at hand that are needed to define an equilibrium.

Definition 1 (Recursive Competitive Equilibrium) Given a government policy $\left\{\phi_{U}, \delta\right\}, a$ recursive competitive equilibrium consists of a tax function $\tau$, value functions $V_{S}$ and $V_{U}$, labor supply functions $L_{S}$ and $L_{U}$, labor demand functions $L_{F S}, L_{F U}, L_{I S}$, and $L_{I U}$, wage functions $w_{S}$ and $w_{U}$, mobility functions $\lambda_{S \rightarrow S}, \lambda_{S \rightarrow U}, \lambda_{U \rightarrow S}$, and $\lambda_{U \rightarrow U}$, all mapping $X$ into $\mathbf{R}_{+}$, policy functions $n_{S}$ and $n_{U}$ mapping $\{S, U\} \times X$ into $\mathbf{R}_{+}$, and a law of motion $g$ mapping $X$ into itself, such that:

(i) The value functions satisfy the following functional equation for $i \in\{S, U\}$ :

$$
V_{i}(x)=\max _{c, n_{S}, n_{U} \geq 0}\left\{c^{\sigma}+\beta\left(n_{S}+n_{U}\right)^{-\epsilon}\left[n_{S} V_{S}\left(x^{\prime}\right)+n_{U} V_{U}\left(x^{\prime}\right)\right]\right\} .
$$

subject to the budget constraint (9) and the law of motion $x^{\prime}=g(x)$.

(ii) For $i, j \in\{S, U\}$, if $\lambda_{i \rightarrow j}(x)>0, n_{j}(i, x)$ attains the maximum in (24).

(iii) The tax function $\tau$ satisfies the government budget constraint (21).

(iv) The wages $w_{S}$ and $w_{U}$ and labor demand $L_{F S}, L_{F U}, L_{I S}$, and $L_{I U}$ satisfy (5)-(8) and (18).

(v) Labor supply $L_{S}$ and $L_{U}$ satisfies (16) and (17).

(vi) Labor supply $L_{S}$ and $L_{U}$ and labor demand $L_{F S}, L_{F U}, L_{I S}$, and $L_{I U}$ satisfy (19) and (20).

(vii) The mobility functions $\lambda_{S \rightarrow S}, \lambda_{S \rightarrow U}, \lambda_{U \rightarrow S}$, and $\lambda_{U \rightarrow U}$ satisfy (10). 
(viii) The law of motion $g$ for the state variable $x$ is given by (4), (22), and (23).

The equilibrium conditions do not include a market-clearing constraint for the goods market, because it holds automatically by Walras' Law. In condition (ii) above, it is understood that parents choose only one type of children. In other words, saying that $n_{S}(S, x)$ attains the maximum in (24) means that $\left\{n_{S}=n_{S}(S, x), n_{U}=0\right\}$ and the consumption $c$ that results from the budget constraint maximize utility. Maximization is only required if a positive number of parents choose the type of children in question. Condition (iii) is the government budget constraint. Condition (iv) requires that wages equal marginal products and that the skilled wage does not fall below the unskilled wage, condition (v) links labor supply to population and education time, condition (vi) is the market-clearing condition for the labor market, condition (vii) requires that for each type of adult the fractions having skilled and unskilled children sum to one, and condition (viii) defines the law of motion.

\section{B Proofs for all Propositions}

Proof of Proposition 1 The profit-maximization problem of a firm in the industrial sector is given by:

$$
\max _{l_{S}, l_{U}}\left\{A_{I}\left(l_{S}\right)^{1-\alpha}\left(l_{U}\right)^{\alpha}-w_{S}(x) l_{S}-w_{U}(x) l_{U}\right\} .
$$

The first-order condition for a maximum with respect to $l_{U}$ gives:

$$
\left(l_{S}\right)^{1-\alpha}=\frac{w_{U}(x)\left(l_{U}\right)^{1-\alpha}}{A_{I} \alpha} .
$$

Plugging this expression back into (25) yields a formulation of the profit maximization problem as a function of unskilled labor only:

$$
\max _{l_{U}}\left\{\frac{w_{U}(x)}{\alpha} l_{U}-w_{S}(x)\left(\frac{w_{U}(x)}{A_{I} \alpha}\right)^{\frac{1}{1-\alpha}} l_{U}-w_{U}(x) l_{U}\right\} .
$$

Since this expression is linear in $l_{U}$, production in the industrial sector will be profitable only if we have:

$$
\frac{w_{U}(x)}{\alpha}-w_{S}(x)\left(\frac{w_{U}(x)}{A_{I} \alpha}\right)^{\frac{1}{1-\alpha}}-w_{U}(x) \geq 0,
$$

which can be rearranged to get:

$$
w_{S}(x)^{1-\alpha} w_{U}(x)^{\alpha} \leq A_{I}(1-\alpha)^{1-\alpha} \alpha^{\alpha},
$$

which is (11). 
The first-order necessary conditions for a maximum of the profit-maximization problem of a firm in agriculture are given by the wage conditions (5) and (6):

$$
\begin{aligned}
& w_{S}(x)=A_{F} \frac{\theta_{S}}{\theta_{S}+\theta_{U}} \frac{L_{F U}^{\theta_{U}}}{L_{F S}^{1-\theta_{S}}} Z^{1-\theta_{S}-\theta_{U}}, \\
& w_{U}(x)=A_{F} \frac{\theta_{U}}{\theta_{S}+\theta_{U}} \frac{L_{F S}^{\theta_{S}}}{L_{F U}^{1-\theta_{U}}} Z^{1-\theta_{S}-\theta_{U}} .
\end{aligned}
$$

Since the objective function is concave, the first-order conditions are also sufficient for a maximum. It is therefore sufficient to show that for any $w_{S}(x), w_{U}(x)>0$ we can find values for skilled and unskilled labor supply $L_{F S}$ and $L_{F U}$ such that (27) and (28) are satisfied. The required values are given by:

$$
L_{F S}=\left(\frac{A_{F}}{\theta_{S}+\theta_{U}}\right)^{\frac{1}{1-\theta_{S}-\theta_{U}}}\left(\frac{\theta_{S}}{w_{S}(x)}\right)^{\frac{1-\theta_{S}}{1-\theta_{S}-\theta_{U}}}\left(\frac{\theta_{U}}{w_{U}(x)}\right)^{\frac{\theta_{U}}{1-\theta_{S}-\theta_{U}}} Z
$$

and:

$$
L_{F U}=\left(\frac{A_{F}}{\theta_{S}+\theta_{U}}\right)^{\frac{1}{1-\theta_{S}-\theta_{U}}}\left(\frac{\theta_{S}}{w_{S}(x)}\right)^{\frac{\theta_{S}}{1-\theta_{S}-\theta_{U}}}\left(\frac{\theta_{U}}{w_{U}(x)}\right)^{\frac{1-\theta_{U}}{1-\theta_{S}-\theta_{U}}} Z,
$$

which are positive for any positive wages $w_{S}(x)$ and $w_{U}(x)$.

Proof of Proposition 2 We consider the following maximization problem:

$$
\max _{E \geq 0,0 \leq f \leq 0}\left\{(w-E)^{\sigma}+\beta E^{1-\epsilon}\left(f / p_{S}+(1-f) / p_{U}\right)^{-\epsilon}\left[f V_{S} / p_{S}+(1-f) V_{U} / p_{U}\right]\right\} .
$$

By assumption, the parameters $\beta, \sigma$ and $\epsilon$ are all strictly bigger than zero and strictly smaller than one. It is also assumed w.l.o.g. that $0<p_{U}<p_{S}$ and $V_{S}, V_{U} \geq 0$ hold. We want to show that there are no interior solutions in $f$, i.e., if there is a solution to the maximization problem above, the optimal $f$ is either zero or one.

To show that there are no interior solutions, assume that we have already determined the optimal $E$. Given this $E$ and the fact that the function to be maximized is twice continuously differentiable in $f$, if there were an interior solution, the optimal $f$ would have to satisfy first- and second-order conditions for a maximum. I solve for the unique $f$ which solves the first-order condition, and show that this $f$ does not satisfy the secondorder condition. This proves that there are only corner solutions.

I will name the maximand $U(\cdot)$. The first and second derivatives of $U$ with respect to $f$ 
are:

$$
\begin{gathered}
\frac{\partial U}{\partial f}=\beta E^{1-\epsilon}\left[-\epsilon\left(\frac{1}{p_{S}}-\frac{1}{p_{U}}\right)\left(\frac{f}{p_{S}}+\frac{1-f}{p_{U}}\right)^{-\epsilon-1}\left(\frac{f V_{S}}{p_{S}}+\frac{(1-f) V_{U}}{p_{U}}\right)\right. \\
\left.+\left(\frac{f}{p_{S}}+\frac{1-f}{p_{U}}\right)^{-\epsilon}\left(\frac{V_{S}}{p_{S}}-\frac{V_{U}}{p_{U}}\right)\right], \\
\frac{\partial^{2} U}{\partial f^{2}}=\beta E^{1-\epsilon} \epsilon\left(\frac{1}{p_{S}}-\frac{1}{p_{U}}\right)\left(\frac{f}{p_{S}}+\frac{1-f}{p_{U}}\right)^{-\epsilon-1} \\
\\
{\left[(1+\epsilon)\left(\frac{1}{p_{S}}-\frac{1}{p_{U}}\right)\left(\frac{f}{p_{S}}+\frac{1-f}{p_{U}}\right)^{-1}\left(\frac{f V_{S}}{p_{S}}+\frac{(1-f) V_{U}}{p_{U}}\right)-2\left(\frac{V_{U}}{p_{U}}-\frac{V_{S}}{p_{S}}\right)\right] .}
\end{gathered}
$$

In the first derivative, for $0 \leq f \leq 1$, the first term within the outer brackets is positive. For an interior solution to be possible, it has to be the case that $V_{S} / p_{S}<V_{U} / p_{U}$, because otherwise the second term is also positive and the first-order condition cannot be satisfied. Therefore if $V_{S} / p_{S} \geq V_{U} / p_{U}$, we are done. For the case that $V_{S} / p_{S}<V_{U} / p_{U}$, setting the first derivative equal to zero and solving for $f$ yields:

$$
f=\frac{\epsilon\left(\frac{V_{U}}{p_{S}}-\frac{V_{U}}{p_{U}}\right)-\left(\frac{V_{S}}{p_{S}}-\frac{V_{U}}{p_{U}}\right)}{(1-\epsilon) p_{U}\left(\frac{V_{S}}{p_{S}}-\frac{V_{U}}{p_{U}}\right)\left(\frac{1}{p_{S}}-\frac{1}{p_{U}}\right)} .
$$

I will now plug this value for $f$ into the second derivative to verify that the second derivative is positive, so that the critical point is not a maximum. The second derivative is positive if the following inequality holds:

$$
(1+\epsilon)\left(\frac{1}{p_{S}}-\frac{1}{p_{U}}\right)\left(\frac{f}{p_{S}}+\frac{1-f}{p_{U}}\right)^{-1}\left(\frac{f V_{S}}{p_{S}}+\frac{(1-f) V_{U}}{p_{U}}\right)-2\left(\frac{V_{S}}{p_{S}}-\frac{V_{U}}{p_{U}}\right)<0 .
$$

Plugging in our value for $f$ yields after some algebra:

$$
\begin{aligned}
(1+\epsilon) \frac{1}{p_{U}}\left(\frac{V_{U}}{p_{S}}-\frac{V_{U}}{p_{U}}\right)<\frac{1}{p_{U}}\left[\epsilon\left(\frac{V_{U}}{p_{S}}-\frac{V_{U}}{p_{U}}\right)-\left(\frac{V_{S}}{p_{S}}-\frac{V_{U}}{p_{U}}\right)\right]+2 \frac{1}{p_{U}}\left(\frac{V_{S}}{p_{S}}-\frac{V_{U}}{p_{U}}\right), \\
\frac{1}{p_{U}}\left(\frac{V_{U}}{p_{S}}-\frac{V_{U}}{p_{U}}\right)<\frac{1}{p_{U}}\left(\frac{V_{S}}{p_{S}}-\frac{V_{U}}{p_{U}}\right), \\
V_{U}<V_{S},
\end{aligned}
$$

Thus if $V_{S}>V_{U}$ the second-order condition for a maximum is not satisfied, and therefore there is no interior maximum. Conversely, if $V_{S}$ were smaller than $V_{U}$, there would be only unskilled children for sure, since they are cheaper to educate. Thus once again we obtain a corner solution. Thus in every case there are only corner solutions. families have 
either unskilled or skilled children, but they do not mix.

Proof of Proposition 3 It is helpful to consider the formulation of the problem in which adults choose the total education cost $E$, so that the number of children equals $E / p_{i}$ for adults who choose to have children of type $i$. The maximization problem in this formulation is:

$$
\max _{0 \leq E \leq w / p_{i}}\left\{(w-E)^{\sigma}+\beta\left(E / p_{i}\right)^{1-\epsilon} V_{i}\right\} .
$$

This can also be written as:

$$
\max _{E \geq 0}\left\{(w-E)^{\sigma}+\beta(E)^{1-\epsilon} \frac{V_{i}}{\left(p_{i}\right)^{1-\epsilon}}\right\} .
$$

Since the costs and utilities of children enter only in the last term, an adult is indifferent between skilled and unskilled children if and only if:

$$
\frac{V_{S}}{\left(p_{S}\right)^{1-\epsilon}}=\frac{V_{U}}{\left(p_{U}\right)^{1-\epsilon}},
$$

Notice that this condition does not depend on the wage of the adult. Also, if condition (31) is satisfied, adults face the same maximization problem regardless whether they decide for unskilled or skilled children. This implies that the optimal total education cost $E$ does not depend on the type of the children. The higher cost of having skilled children will be exactly made up by a lower number of children.

Proof of Proposition 4 Since we assume $w_{S}>w_{U}$, i.e., the skilled wage strictly exceeds the unskilled wage, the time of skilled parents is more expensive. We then have:

$$
\frac{\phi w_{S}+\phi_{S} w_{S}+\rho}{\phi w_{S}-\phi_{U} w_{U}+\rho}<\frac{\phi w_{U}+\phi_{S} w_{S}+\rho}{\phi w_{U}-\phi_{U} w_{U}+\rho},
$$

the ratio of the total cost of skilled child to that an unskilled child is lower for skilled parents than for unskilled parents. In other words, skilled children are relatively cheaper for skilled parents, and unskilled children are relatively cheaper for unskilled parents. Since in equilibrium there must be a positive number of children of each type, at least some skilled parents must have skilled children, and at least some unskilled parents must have unskilled children. Moreover, it follows from Proposition 3 that both types of parents can be indifferent between both types of children only if the price ratio between skilled and unskilled children is the same. This cannot be the case since the wage and therefore the time cost differs, thus just one type of parent can be indifferent. 


\section{Policies in Brazil, Korea, and England}

Korea and Brazil are polar cases in terms educational and child-labor policies. Korea instituted a system of free, compulsory education from the ages of 6 to 12 in 1949, right after independence. After the Korean war the government instituted a 'Compulsory Education Accomplishment Plan," and by 1959 the primary enrollment rate reached 96\%. Strictly enforced compulsory education served as an effective constraint on child labor, in addition to direct child-labor restrictions. According to the International Labor Organization (ILO), in 1960 only $1.1 \%$ of the children from zero to fifteen years were economically active, and by 1985 only $.3 \%$ of the children between ages ten and fourteen participated in the labor market. By the letter of the law, free and compulsory education was introduced in Brazil already in 1930. In practice, however, primary schooling was not available in many rural areas, and to the present day the available schools are often of poor quality. In 1965 the primary enrollment rate was still below 50\% in rural areas. The neglect of primary education in Brazil can also be gauged from education finances. In 1960, less than $10 \%$ of public spending on education was directed to the primary sector, while the corresponding figure was about $70 \%$ for Korea. Child-labor regulation is less restrictive in Brazil in Korea. While Korea signed on to an ILO convention that rules out child labor under the age of 14, Brazil did not. The minimum age for employment in Brazil is now 12, and even this limit is not always enforced. In $198518.7 \%$ of the children between ages ten and fourteen participated in the labor market. Child labor is even more prevalent among male children, with $25.3 \%$ listed as economically active in 1987 . The different policies in Brazil and Korea are also reflected in educational outcomes. In both countries average years of schooling increase over time, but the increase is much faster in Korea. In 1960, the difference in average years of schooling between Korea and Brazil was less than a year. By 1985, the difference increased to more than four years, so that Koreans on average have more than twice as much schooling as Brazilians. Another measure of educational success is given by adult illiteracy rates. In 1960,39\% of adult Brazilians were illiterate, compared to $29 \%$ of adult Koreans. In 1995, in Brazil illiteracy is still at $16.7 \%$, while Koreans are almost completely literate with an illiteracy rate of only $2 \%$. In Brazil illiteracy is high even among groups who went to school only recently. In 1991, illiteracy was $12.1 \%$ for the age group from 15 to 19 years.

In England, education was not widespread at the beginning of the Industrial Revolution. In 1780 , only about $50 \%$ of brides and grooms were able to sign their name. Education expanded only slowly throughout most of the nineteenth century. Public education also started to expand in the nineteenth century, but there were large regional differences and no universal access to affordable education. The situation changed drastically with the Victorian education reforms. The Forster Education Act of 1870 placed primary education under public control. In 1880 compulsory schooling was introduced, and starting in 1891 primary education was free. While schooling quality is hard to measure, literacy data suggests that the reforms were successful. While in 1880 about $15 \%$ of grooms and $20 \%$ of brides were unable to sign their name, these numbers decreased to less than $2 \%$ until 
1910. The first child-labor restrictions were put in place with the Factory Act of 1833. Only a small set of industries was affected, however, and Nardinelli (1980) concludes that the impact on child labor was small. The Factory Acts were amended in 1844 and 1874, when the minimum age for child laborers was raised to 10. At that time the restrictions became universal, instead of being limited to certain industries. Compulsory schooling laws also had an effect on child labor. As a result, the incidence of child labor was decreasing late in the nineteenth century. Activity rates for children aged from ten to fourteen reached a peak 1861 , when $29 \%$ of all children in that age group were economically active. In 1871, the number was still at $26 \%$, but then it fell to about $20 \%$ in 1881 and $1891,17 \%$ in 1901 , and $14 \%$ in 1911.

\section{Notes on Computation}

Within the Malthusian regime and the growth regime, the model can be computed via standard value function iteration on a discretized state space. The initial guess for the value functions is computed by setting the number of children to zero, so that utility stems from consumption only. During the iterations, for a given state $x$, the algorithm finds a state $x^{\prime}$ in the next period such that the resulting fertility decisions of adults are consistent with state $x^{\prime}$. After the iterations converge, the equilibrium law of motion can be used to compute steady-state values. Alternatively, the steady state can be computed by solving a system of equations that defines the steady state.

In principle it is possible to compute the entire model, encompassing the Malthusian regime, the transition, and the growth regime, with the same method described above. However, since the state vector is four-dimensional, computations would either take very long or would be imprecise. Therefore I use a shooting algorithm that directly computes the equilibrium path over $T$ periods from any starting value $x_{0}$ for the state vector. The computations are started a number of periods before the industrial technology becomes competitive. The number of periods $T$ to be computed has to be chosen sufficiently large such that the economy is close to the balanced growth path at $T$. Whether this is the case can be checked by computing the growth regime as described above before computing the transition. The algorithm is not guaranteed to converge, but it works well in practice. 


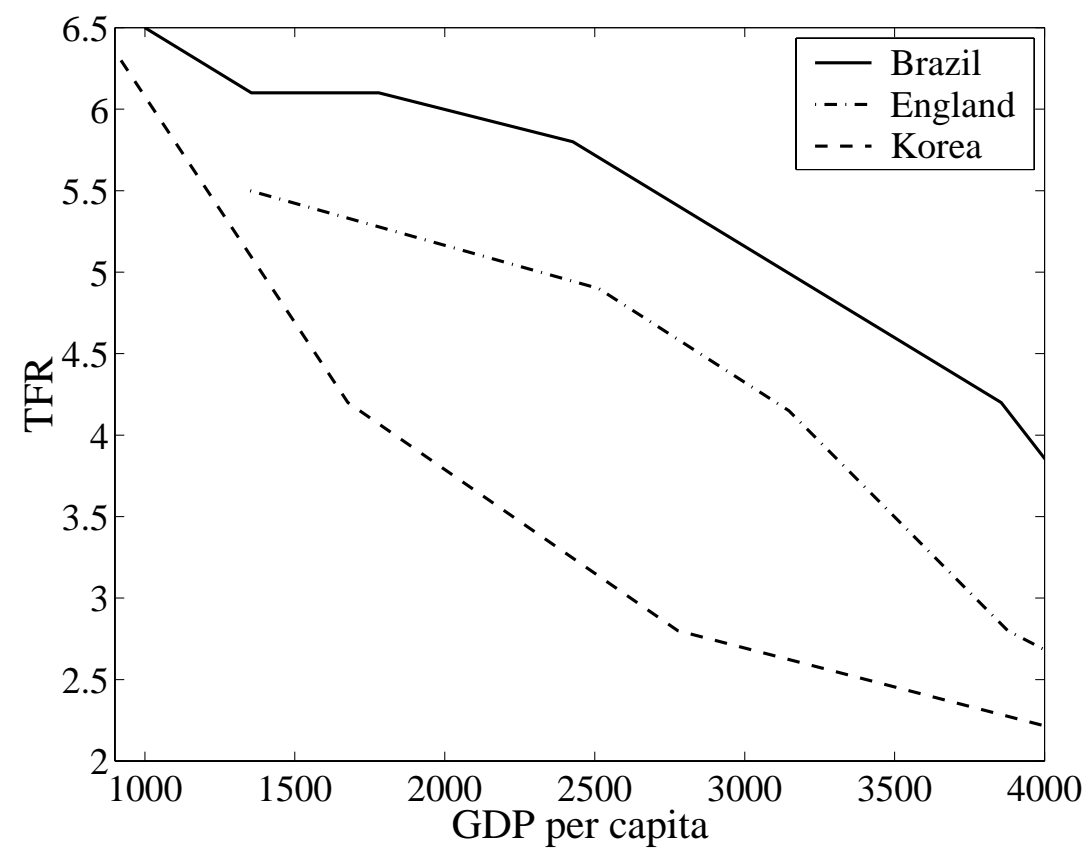

The graph covers approximately the periods 1820-1914 for England, 1945 to 1980 for Brazil, and 1960 to 1985 for Korea.

Figure 1: Fertility Decline from Peak Relative to GDP per capita in Brazil, Korea, and England
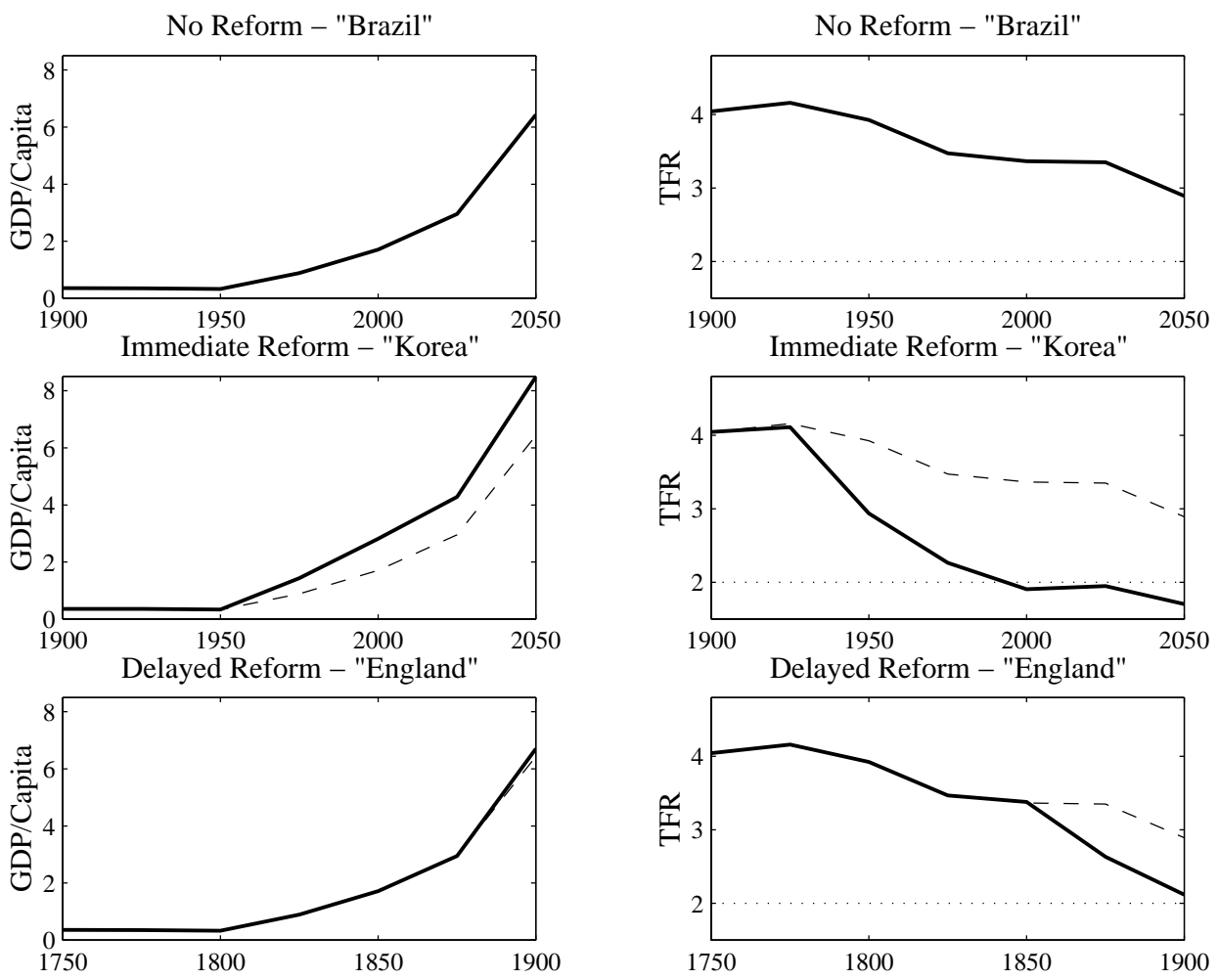

Figure 2: Outcome with Different Policies (Dotted Lines are Brazilian Outcomes as a Benchmark) 

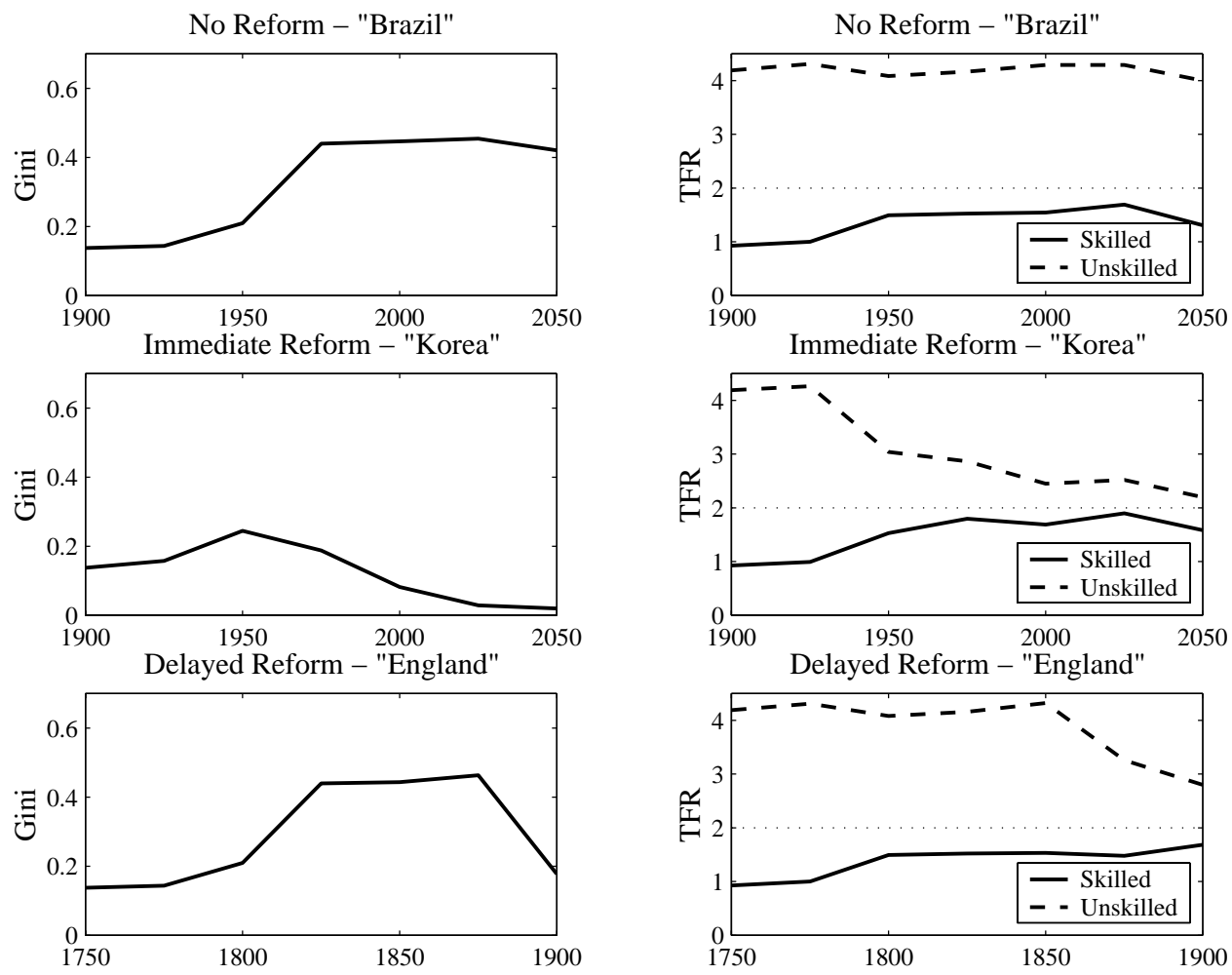

Figure 3: Gini Coefficients and Fertility Differentials
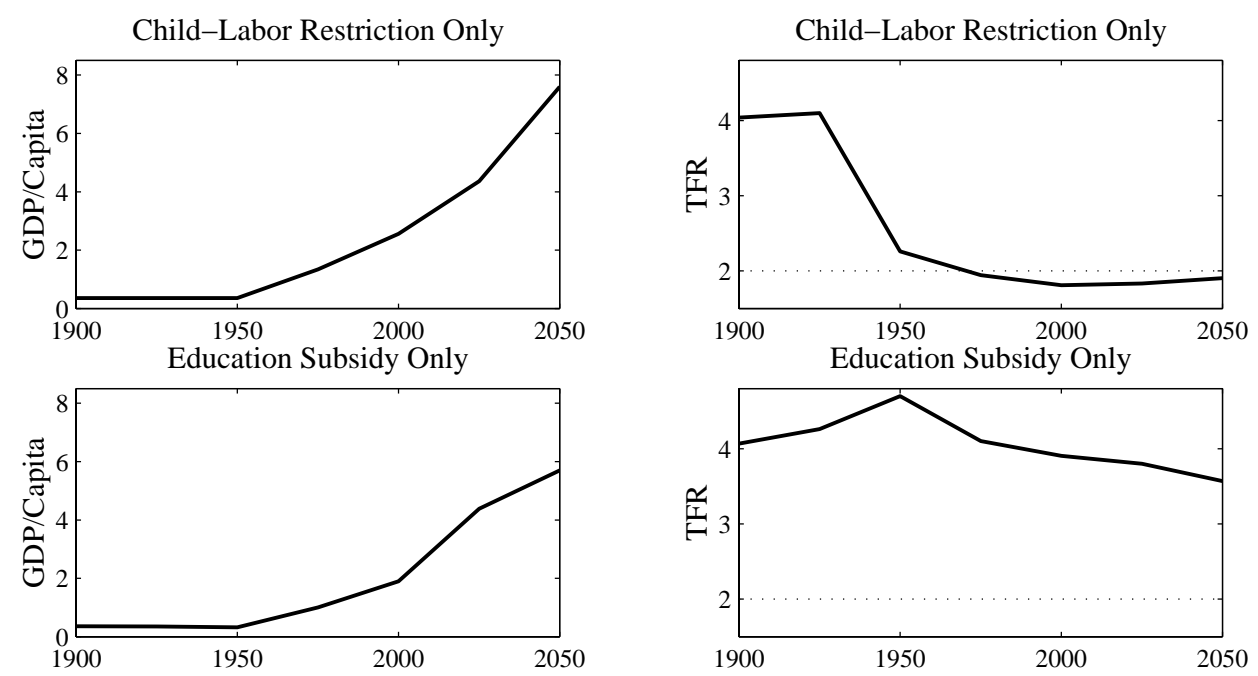

Figure 4: Outcome with Isolated Policies 